\title{
Revue bibliographique quantitative sur l'utilisation des hormones anabolisantes à action stéroïdienne chez les ruminants en production de viande. I. Performances zootechniques
}

\author{
P Schmidely
}

INA-PG, station de nutrition et alimentation, 16, rue Claude-Bernard, 75231 Paris cedex

(Reçu le 4 janvier 1993; accepté le 3 juin 1993)

\begin{abstract}
Résumé - Les réponses moyennes et les facteurs de variation des performances zootechniques (vitesse de croissance, matière sèche ingérée, bilan azoté et composition corporelle) ont été étudiés de façon quantitative sur une base de données constituées de plus de 150 études chez les ruminants en production de viande, traités par des substances anabolisantes naturelles ou de synthèse utilisées seules ou en associations. La vitesse de croissance est accrue de $18 \%$ chez les bovins et de $16 \%$ chez les ovins. L'augmentation maximale du GMQ est obtenue avec une association d'un œstrogène et d'un androgène, en particulier chez l'animal castré, tandis que la réponse apparaît légèrement plus faible chez le mâle entier. D'autres facteurs comme l'âge, la durée et la posologie du traitement, le niveau et la qualité de l'alimentation paraissent influer l'accroissement du GMQ par ces hormones. Chez le mâle castré traité par des associations œstrogène/androgène et chez la jeune femelle traitée par des androgènes, la composition de la carcasse est modifiée dans le sens d'un accroissement du pourcentage de muscles et d'une réduction de l'état d'engraissement. Chez le mâle entier, il y a une tendance à l'accroissement de l'adiposité surtout par traitement avec des œstrogènes. L'étude de la composition chimique du corps vide ou de la carcasse tend à montrer un léger accroissement de la teneur en eau au détriment de celle en lipides, principalement chez le mâle castré. Les effets de ces substances au niveau de la composition chimique de la viande paraissent peu significatifs.
\end{abstract}

hormones anabolisantes / engraissement / composition corporelle / ruminant / revue quantitative

Summary - Quantitative review on the use of anabolic hormones in ruminants for meat production. I. Animal performance. Mean responses and factors of variation for animal performance (growth rate, dry matter intake, nitrogen balance, meat and body composition) were quantitatively studied through a data base constituted of over 150 papers related to the fattening of ruminants treated with natural or synthetic anabolic compounds used alone or in combination. The overall increase in $A D G$ was $18 \%$ in beef and $16 \%$ in sheep. The greatest improvement in ADG was obtained with a combination of androgen and oestrogen, particularly in castrated males, whereas uncastrated 
males responded to a lesser extent. Others factors such as age, dose level, length of trial, feeding level and quality of diet appear to be an important influence on the changes in ADG upon treatment. In castrated animals treated with the oestrogen/androgen combination, like in females treated with androgens, the muscle percentage of the carcass is increased, whereas fat is decreased. In uncastrated males, there was a tendency for increased fatness, particularly with oestrogens. In empty bodies or carcasses, the water content is slightly increased, whereas the lipid content is decreased, particularly in castrated males. The alteration of meat chemical composition after treatment is low.

anabolic hormones / fattening / body composition / ruminant / quantitative review

\section{INTRODUCTION}

Les différences de croissance et le dimorphisme sexuel sont principalement liés à des différences de sécrétion endogène d'hormones sexuelles ainsi qu'à des différences de nombre, d'affinité des récepteurs à ces hormones, et d'activité postrécepteur : le mâle entier grandit plus vite et il est plus maigre que le mâle castré, luimême moins gras que la femelle. Ces observations sont à la base de l'utilisation des hormones sexuelles comme promoteurs de croissance (anabolisants ou agents répartiteurs) au travers de l'accroissement de la rétention azotée dans le muscle squelettique principalement. En effet, le pourcentage de protéines alimentaires retenues sous forme de protéines corporelles dépend essentiellement du métabolisme intermédiaire, dont l'efficacité de transformation décroît avec l'âge : $80 \%$ des protéines alimentaires sont retenues dans l'organisme durant les 20 premiers j de vie contre moins de $50 \%$ vers $80 j$ d'âge (Van der Wal, 1976). Le contrôle du métabolisme par l'apport d'hormones peut donc permettre d'accroître la rétention azotée.

Les anabolisants hormonaux utilisés ont des propriétés équivalentes des hormones sexuelles endogènes (développement des caractères sexuels...), en plus d'une activité anabolisante bien qu'il soit difficile de faire la différence entre les deux types de propriétés. Ils peuvent être classifiés selon leur origine (endogène ou de synthèse), leur nature chimique (stéroïde ou non) ou leur activité (androgène, œstrogène ou progestagène). Le principe général de leur utilisation est basé sur le fait que, pour obtenir une croissance maximale, l'animal doit présenter une concentration en cestrogène voisine de celle d'une jeune femelle associée à une concentration en androgènes équivalente de celle d'un jeune mâle. Les anabolisants les plus utilisés sont donc les androgènes chez la femelle, les œstrogènes chez le mâle et les associations d'androgène et d'œstrogène ou d'œstrogène et de progestagène chez le castrat. Plus récemment cependant, l'utilisation d'associations d'anabolisants s'est généralisée aux individus mâles non castrés avec des résultats positifs.

L'utilisation des anabolisants a déjà fait l'objet de revues de synthèse (Baker et Arthaud, 1972 ; Galbraith et Topps, 1981 ; Van der Wal et Berende, 1984 ; Unruh, 1986 ; Anderson, 1990). Cependant, en dépit de ces revues, la production scientifique a été assez considérablement enrichie ces derniers temps, conduisant à approfondir les connaissances sur l'efficacité de ces substances et sur leur mode d'action. Dans cette revue, nous nous limiterons à quantifier l'efficacité de ces molécules sur la croissance, l'efficacité alimentaire et la composition corporelle, ainsi que les facteurs de variation susceptibles de modifier la réponse animale. Dans une seconde 
revue (Schmidely, 1993), nous étudierons les mécanismes d'action de ces molécules en relation avec les modifications de croissance induites.

\section{PERFORMANCES DE CROISSANCE ET EFFICACITÉ ALIMENTAIRE}

\section{Modification de la vitesse de croissance}

\section{Amplitude des améliorations}

Les résultats de plus de 150 essais publiés dans la littérature depuis 1975 ont été compilés afin d'étudier la réponse aux anabolisants et les facteurs de variation. Cette compilation représente un effectif de plus de 6000 bovins et de plus de 1000 ovins de tous sexes. Seules les études récentes ont été considérées dans le but de s'affranchir de l'évolution des performances liées à la sélection génétique.

Tous types d'anabolisants confondus (fig 1a,b), l'amélioration moyenne de la vitesse de croissance (GMQ, gain moyen quotidien) est de $16 \%$ chez les bovins et $18 \%$ chez les ovins quelque soit le sexe des animaux traités, et ce dans les cas où le niveau d'alimentation n'est pas limitant pour la croissance. Cependant cette valeur moyenne est associée à une forte dispersion des résultats (écart-type $E T=10 \%$, soit un coefficient de variation de $60 \%$ ). Les facteurs de variation de la réponse aux anabolisants sont désormais assez bien connus et peuvent être regroupés en 3 catégories :

i) les facteurs liés à l'animal : le sexe et l'âge avec leurs influences sur les systèmes hormonaux et la capacité de rétention azotée, l'espèce animale et le niveau de performance qui conditionne en particulier le mode d'expression de la modification des vitesses de croissance ( $\mathrm{g} / \mathrm{j}$ ou $\%)$;
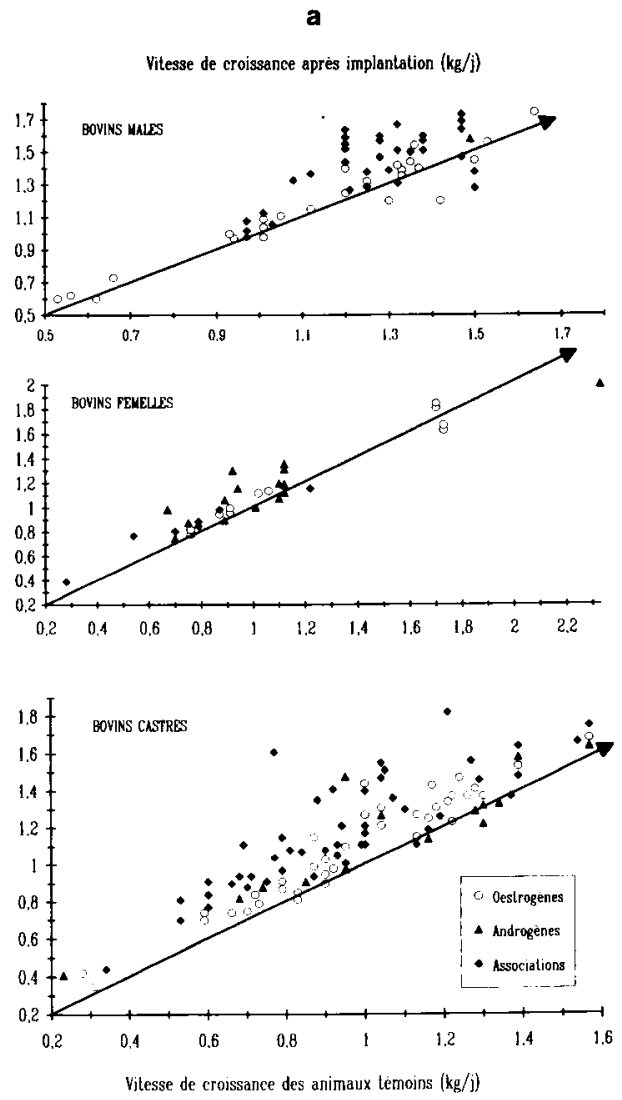

b

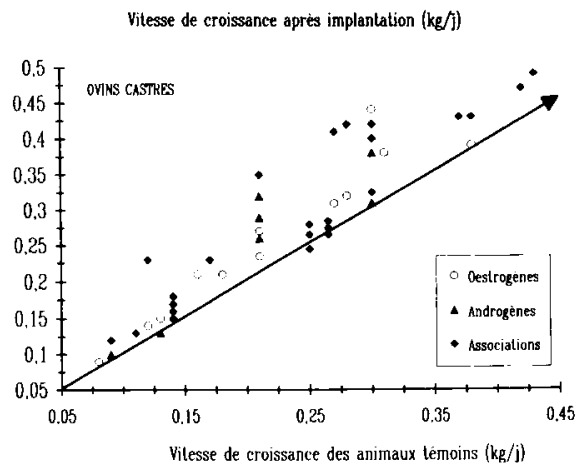

Fig 1a. Influence de diverses préparations anabolisantes sur la croissance des bovins. b. Influence de diverses préparations anabolisantes sur la croissance des ovins. 
ii) la densité nutritive de la ration en azote et en énergie qui détermine l'état nutritionnel de l'animal et sa capacité de réponse à un stimulus de croissance ;

iii) le type de molécule utilisée et sa posologie exprimée en termes de dose administrée, de délai entre la pose de l'implant et l'abattage, de fréquence des implantations ou de mode de diffusion du principe actif.

\section{Utilisation d'œestrogènes}

Pour les molécules utilisées (œstradiol$17 \beta$ ( $E 17 \beta)$, zéranol (Zer), diéthylstilbestrol (DES), hexoestrol (Hex)) chez le bovin mâle entier, la compilation des résultats de 35 lots (Van der Wal et al, 1975a; Grandadam et al, 1975 ; Levy et al, 1976 ; Martin et Stobb, 1978; Martin et al, 1979; Ford et Gregory, 1983 ; Greathouse et al, 1983 ; Gregory et Ford, 1983 ; Price et al, 1983 ; Prior et al, 1983 ; Schanbacher et al, 1983 ; Galbraith et al, 1984 ; Staigmiller et al, 1985 ; Vanderwert et al, 1985b ; Calkins et al, 1986 ; Gray et al, 1986 ; Silcox et al, 1986 ; Fischer et al, 1986b ; Unruh et al, 1986a; Hopkins et Dikeman, 1987 ; Peters et al, 1988; Schakelford et al, 1992) (fig 2) révèle une faible amélioration de $4 \%$ (ET $=7 \%$ ) du GMQ avec des valeurs extrêmes comprises entre $-0,22 \mathrm{~kg} / \mathrm{j}$ (Prior et al, 1983) et $+0,20 \mathrm{~kg} / \mathrm{j}$ (Gregory et Ford, 1983). Sur l'intervalle de GMQ étudiés (tableau 1), le gain supplémentaire après traitement est de l'ordre de $0,04 \mathrm{~kg} / \mathbf{j}$ $(E T=0,08)$. Cependant lorsque le niveau de performance des témoins s'accroît, l'écart entre témoins et traités semble se réduire (fig 3). Nous avons donc ajusté les écarts de performances (dGMQ $=\mathrm{GMQ}$ (Implant) - GMQ(Témoin)) par un modèle du type (tableau I) :

$$
\begin{aligned}
\mathrm{dGMQ} & =\mathrm{a}+\mathrm{b}^{*} \mathrm{GMQ} \text { (Témoin) } \\
& +\mathrm{c}^{*} \mathrm{GMQ} \text { (Témoin) }
\end{aligned}
$$

Les valeurs des paramètres de cette équation montrent que l'amélioration maxi-
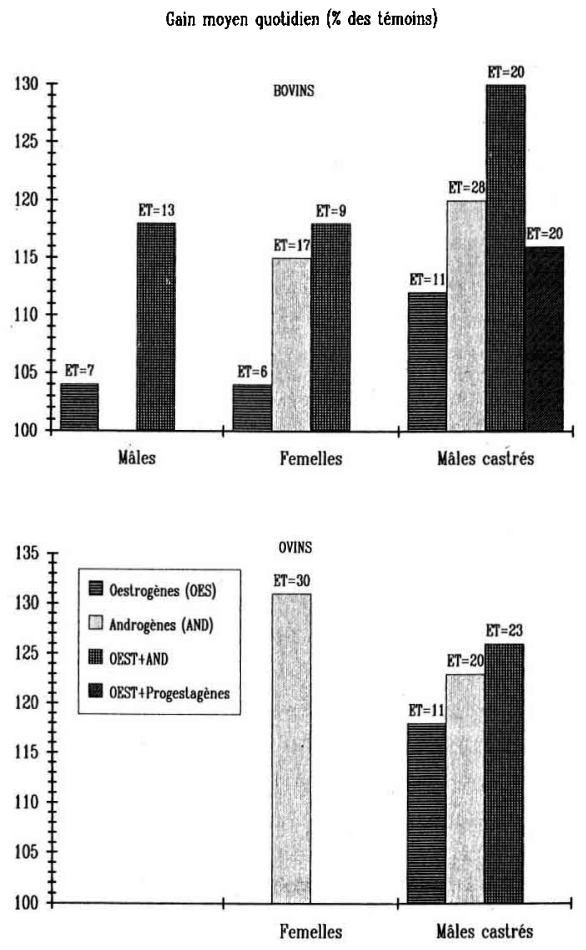

Fig 2. Modification de la vitesse de croissance par les anabolisants : effets du sexe.

male des performances par les œestrogènes est de l'ordre de $0,06 \mathrm{~kg} / \mathrm{j}$ obtenus vers $0,95 \mathrm{~kg} / \mathrm{j}$ de $\mathrm{GMQ}$, alors que, vers $1,6 \mathrm{~kg} / \mathrm{j}$, l'écart après traitement s'annule. Cette croissance correspond approximativement à la vitesse de croissance maximale d'un jeune taurillon dans notre échantillon de poids. Ainsi chez le jeune mâle en croissance, l'effet des œstrogènes sur la vitesse de croissance est peu important comme l'avaient déjà signalé Baker et Arthaud (1972) dans leur revue.

Chez le bovin mâle castré qui a été le type animal le plus étudié, l'augmentation des performances (fig 2) est en moyenne de $12 \%(E T=11 \%, n=46$ lots comparés issus des données de Borger et al, 1973; 


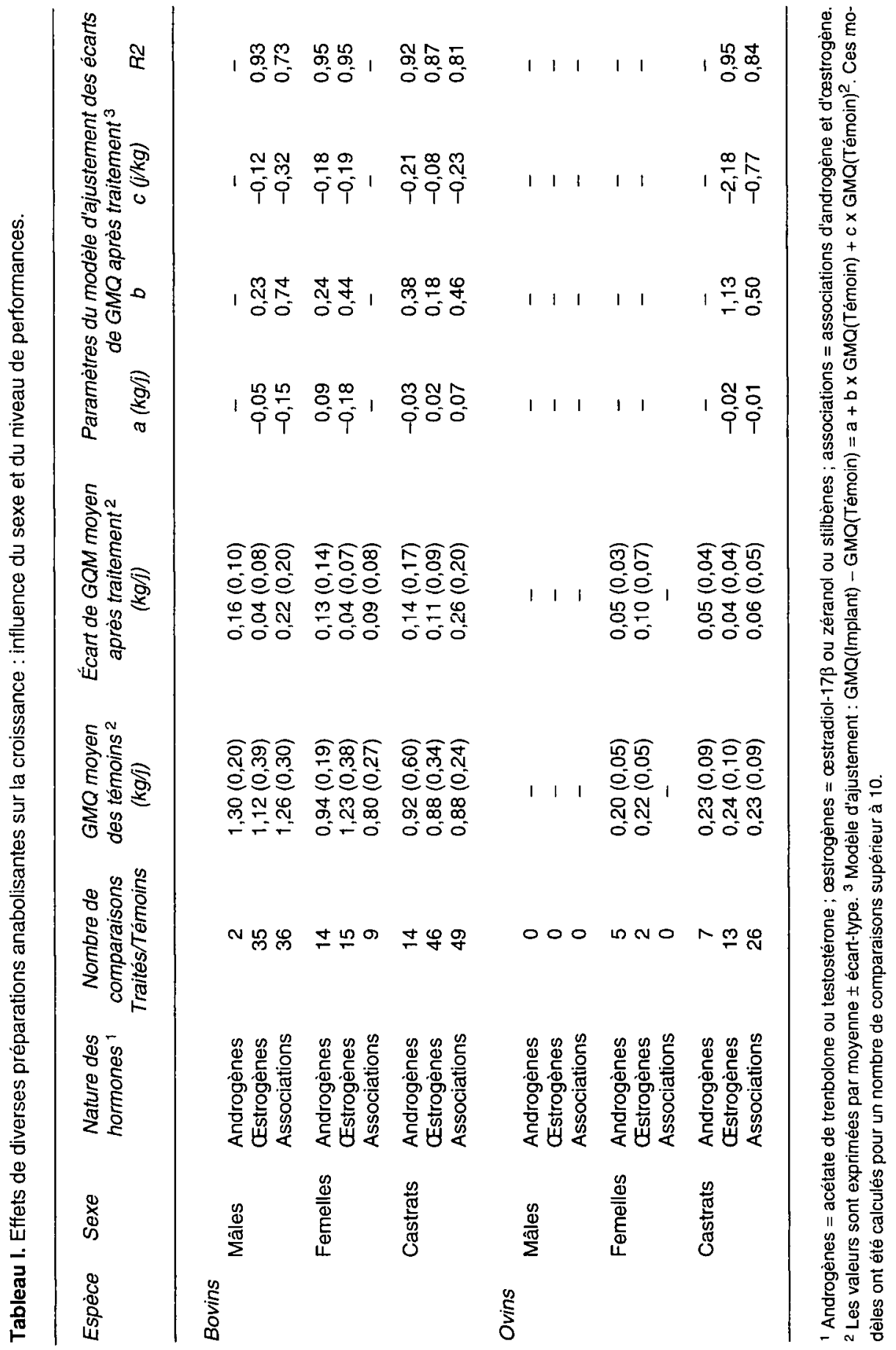


Ecart de vitesse de croissance $(\mathrm{kg} / \mathrm{j})$
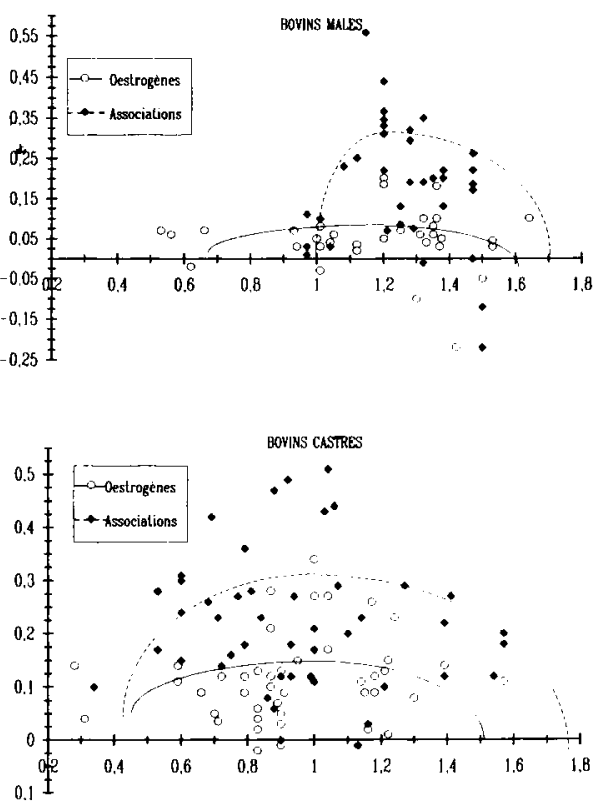

Vilesse de croissance des animaux temoins $(\mathrm{kg} / \mathrm{j})$

Fig 3. Effets du niveau de performances sur l'accroissement de la vitesse de croissance après traitement par diverses préparations anabolisantes chez les bovins.

Galbraith et Watson, 1978; Harris et al, 1979 ; Utley et al, 1980 ; Drennan et al, 1981 ; Heitzman et al, 1981 ; Rumsey et al, 1981; Turner et al, 1981 ; Cohen et Cooper, 1983 ; Prior et al, 1983 ; Roche et Davis, 1983; Schanbacher et al, 1983 ; Basarab et al, 1984 ; Gopinath et Kitts, 1984 ; Vandenwert et al, 1985a,b ; Phillips et al, 1986 ; Rode, 1987 ; Williams et al, 1987 ; Hunter et Vercoe, 1988 ; Lemieux et al, 1988 ; Newbold et al, 1988 ; Southgate et al, 1988 ; Bass et al, 1989a ; Apple et al, 1991 ; Dawson et al, 1991 ; Williams et al, 1991 ; Bartle et al, 1992), avec des améliorations pouvant atteindre $50 \%$ (Hun- ter et Vercoe, 1988) pour des animaux alimentés à l'entretien ou à faible vitesse de croissance, mais aussi des réductions de performances (Schanbacher et al, 1983). Ces différences peuvent être dues soit à une durée trop importante entre la pose de l'implant et l'abattage (voir "Principaux facteurs de variation de la réponse aux anabolisants"), soit à des doses trop fortes d'œstrogènes pouvant conduire à la fermeture des épiphyses osseuses lors de traitements précoces (Van Sickle, 1985).

Sur cet échantillon, l'écart de GMQ est voisin de $0,11 \mathrm{~kg} / \mathrm{j}(E T=0,09 \mathrm{~kg} / \mathrm{j}$, tableau I) ; l'espérance maximale d'accroissement des performances est du même ordre: $0,12 \mathrm{~kg} / \mathrm{j}$ au voisinage de GMQ de $1,1 \mathrm{~kg} / \mathrm{j}$, cet écart s'annulant pour des gains de $1,7 \mathrm{~kg} / \mathrm{j}$. Le traitement des animaux castrés par les cestrogènes est donc positif et le plus souvent supérieur aux résultats obtenus sur animaux entiers dans des conditions expérimentales équivalentes (Vanderwert et al, 1985b). Cependant, lors de sous-alimentation ou de perte de poids (Hunter et Vercoe, 1988), les œstrogènes n'améliorent $\mathrm{ni}$ la vitesse de croissance $\mathrm{ni}$ l'efficacité alimentaire, ce qui peut être lié au fait qu'ils ne réduiraient par le métabolisme d'entretien chez l'animal sousalimenté.

Chez les ovins mâles castrés (fig 2), l'accroissement du GMQ est en moyenne de $0,04 \mathrm{~kg} / \mathrm{j}(E T=0,04 \mathrm{~kg} / \mathrm{j})$ en moyenne, ie $18 \%(\mathrm{ET}=11 \%, n=13$ lots comparés issus des données d'Olsen et al, 1977 ; Wiggins et al, 1979; Donaldson et al, 1981; Quirke et Sheehan, 1981; Wangness et al, 1981 ; Muir et al, 1983 ; Rhind et al, 1984 ; Singh et al, 1985 ; Hunter et al, 1987 ; Alderson et al, 1988 ; Hatendi et al, 1988 ; Field et al, 1990 ; Galbraith et al, 1990 ; Hutcheson et al, 1992). Cette valeur moyenne ne diffère pas statistiquement de la valeur obtenue sur les bœufs.

Chez la femelle, l'utilisation d'œestrogènes permet de faibles améliorations du 
GMQ (fig 2), de l'ordre de $4 \%$ (ET $=6 \%$, $n=15$ lots comparés à partir des données de Price et Makarechian, 1982 ; Chaudhary et al, 1985 ; Deutscher et al, 1986; Cohen et al, 1987 ; Prichard et al, 1989a; Kirkwood et al, 1991 ; Makarechian et al, 1991 ; Moran et al, 1991 ; Zarkawi et al, 1991) soit en moyenne $0,045 \mathrm{~kg} / \mathrm{j}$, équivalentes de celles obtenues sur bovins entiers, l'amélioration maximale étant de 0,07 $\mathrm{kg} / \mathrm{j}$. Les brebis semblent mieux répondre (Sinnet-Smith et al, 1983; Sharpe et al, 1986) en dépit d'une forte disparité (fig 2). Les performances les plus importantes sont obtenues lors d'implantations précoces ou répétées (Cohen et al, 1987 ; Prichard et al, 1989b ; Kirkwood et al, 1991), ce qui semble logique compte tenu du fait que les œstrogènes sont sécrétés en grande quantité chez la femelle au cours de la phase de croissance maximale. $\dot{A}$ l'inverse, chez l'animal âgé ou à faible vitesse de croissance, aucune amélioration n'est obtenue (Chaudhary et al, 1985 ; Makarechian et al, 1991 ; Zarkawi et al, 1991) du fait d'une maturité squelettique déjà achevée.

\section{Utilisation d'androgènes}

L'utilisation d'androgènes (testostérone (Test), acétate de trenbolone (TBA)) à des fins de stimulation de croissance chez le mâle entier n'a été que rarement étudiée et n'a montré qu'une efficacité peu marquée (TBA, Hunt et al, 1991).

Chez les bovins mâles castrés, l'utilisation de TBA ou de Test (fig 2) accroît le GMQ en moyenne de $20 \%$ (ET $=28 \%$ ) sur l'échantillon de 14 lots disponibles (Galbraith et Watson, 1978; Drennan et al, 1981 ; Heitzman et al, 1981; Hunter et Vercoe, 1987; Hunter, 1989 ; Hunter et Magner, 1990a ; Apple et al, 1991; Hunt et al, 1991 ; Bartle et al, 1992). L'écart de GMQ est de l'ordre de $0,14 \mathrm{~kg} / \mathrm{j}(E T=0,17$ $\mathrm{kg} / \mathrm{j}$, tableau i), ce qui confirme que les androgènes sont plus efficaces que les œstrogènes pour stimuler la croissance des bovins castrés. Chez les ovins castrés ( $n=7$ lots comparés à partir des données de Schanbacher et al, 1980 ; Donaldson et al, 1981 ; Quirke et Sheedan, 1981 ; Singh et al, 1985), l'amélioration des performances est du même ordre que chez les bovins, et supérieure à l'amélioration obtenue avec les œstrogènes.

Chez les bovins femelles, l'utilisation de TBA ou de Test augmente le GMQ en moyenne de $15 \%$ (ET $=17 \%$ sur 14 lots comparés issus des données de Little et al, 1979 ; Galbraith, 1980 ; Henricks et al, 1982 ; Donaldson et Heitzman, 1983; Garnsworthy et al, 1986 ; Croose et al, 1987 ; Faulkner et al, 1989 ; Zarkawi et al, 1991), soit un accroissement moyen de $0,13 \mathrm{~kg} / \mathrm{j}$ (tableau I), avec une espérance maximale de gain supplémentaire de 0,16 $\mathrm{kg} / \mathrm{j}$ situé vers un GMQ de 0,7 kg/j. Ceci montre que l'efficacité des androgènes estplus grande que celle des œstrogènes pour stimuler la croissance des femelles. Cependant des effets secondaires défavorables comme la réduction de la durét du cycle œestral ou l'inhibition de la maturation folliculaire (Lindsay et al, 1984 ; Zarkawi et al, 1991) ont pu être observés. Les données peu nombreuses sur ovins (SinnetSmith et al, 1983 ; Sharpe et al, 1986 ; Sulieman et al, 1992) font apparaitre un effet positif plus important que chez les bovins mais avec une plus grande disparité des résultats (fig 2, tableau I).

\section{Les associations d'un œstrogène et d'un androgène}

Ce sont les associations androgène/ œstrogène qui ont été les plus utilisées surtout chez l'animal castré. Chez le bœuf (49 lots comparés à partir des données de Galbraith et Watson, 1978; Harris et al, 1979 ; Drennan et al, 1981 ; Galbraith et Patterson, 1981; Heitzman et al, 1981 ; Galbraith et Geraghty, 1982; Griffiths, 1982 ; Lobley et al, 1982 ; Galbraith et al, 
1983 ; Roche et Davis, 1983; Kay et Reith, 1984 ; Peters et al, 1984 ; Lobley et al, 1985 ; Steen, 1985 ; Keane et Drennan, 1987 ; Henricks et al, 1988 ; Lemieux et al, 1988 ; Ouali et al, 1988 ; Southgate et al, 1988 ; Steen, 1988 ; Lee et al, 1990 ; Apple et al, 1991 ; Bartle et al, 1992 ; Hongerholt et al, 1992), le gain moyen supplémentaire permis est de l'ordre de $0,26 \mathrm{~kg} / \mathrm{j}$ (tableau I), soit $30 \%(E T=20 \%)$. L'analyse du modèle non linéaire montre que, sur une échelle de GMQ comprise entre 0,35 et $1,40 \mathrm{k} / \mathrm{j}$, l'accroissement maximal de performances de $0,30 \mathrm{~kg} / \mathrm{j}$ est atteint vers un GMQ de $1 \mathrm{~kg} / \mathrm{j}$ et il s'annule pour un GMQ de $2 \mathrm{~kg} / \mathrm{j}$, ce qui représente probalement une croissance maximale correspondant à un niveau optimal sanguin d'œstrogène et d'androgène. Cette valeur de l'écart entre implantés et témoins est proche de celles revues par Anderson (1990) et par Lambot et al (1983a) par compilation d'un nombre plus faible de données sur ce type d'animal. Cependant dans certaines expériences, des différences plus importantes ont été obtenues: entre $+0,40$ et $+0,60 \mathrm{~kg} / \mathrm{j}$ (Galbraith et al, 1983 ; Ouali et al, 1988; Steen, 1988), surtout, semble-t-il, lorsque les animaux sont en phase de croissance compensatrice. La même tendance (tableau I) est observée chez le mouton castré avec $+25 \%$ de GMQ pour les 28 lots comparés (Coelho et al, 1981; Donaldson et al, 1981 ; Quirke et Sheehan, 1981; Yasin et Galbraith, 1981 ; Galbraith, 1983 ; SinnetSmith et al, 1983; Singh et al, 1984 ; Singh et al, 1985 ; Coelho et al, 1986 ; Sulieman et al, 1986 ; Sulieman et al, 1988 ; Payne et Cope, 1991) bien que l'accroissement de la réponse en terme de GMQ paraisse un peu plus faible (fig 2).

Plus récemment chez le mâle entier, les associations androgène/œstrogène ont été utilisées avec succès (fig 2). L'écart de performance est un peu plus faible que celui obtenu sur les bœufs : $+0,22 \mathrm{~kg} / \mathrm{j}$ soit
$+18 \%,(E T=13 \%)$ pour les 42 comparaisons considérées (Grandadam et al, 1975 ; Van der Wal et al, 1975a ; Gielen et al, 1982 ; Lambot et al, 1982 ; Fabry et al, 1983 ; Fischer et al, 1986a,b; Johnson et al, 1986 ; Lambot et al, 1983a; Silcox et al, 1986; Toullec et Manis, 1986 ; Henricks et al, 1988 ; Istasse et al, 1988 ; Lee et al, 1990 ; Hunt et al, 1991 ; Bartle et al, 1992). Cet écart est maximal $(+0,28 \mathrm{~kg} / \mathrm{j})$ au voisinage de $1,2 \mathrm{~kg} / \mathrm{j}$ de gain et s'annule vers $2 \mathrm{~kg} / \mathrm{j}$. Cette valeur est un peu plus faible que celle obtenue par Lambot et al (1983a) sur un échantillon plus limité en effectif et une plage de variation de GMQ plus faible $(0,60$ à $1,30 \mathrm{~kg} / \mathrm{j})$. En pratique, des écarts pouvant atteindre $+0,60$ $\mathrm{kg} / \mathrm{j}$ ont été rapportées pour des animaux de type mixte, implantés de façon répétititive (Lambot et al, 1982).

Chez le bovin femelle, les données concernent uniquement les associations E17 $\beta / T B A, E 17 \beta / T e s t$ ou Zer/TBA. Les résultats positifs de $+18 \%$ en moyenne pour les 9 comparaisons considérées (Utley et al, 1976 ; Little et al, 1979 ; Goodman et al, 1982 ; Jones, 1982 ; Keane et Drennan, 1987 ; Frisch et Hunter, 1990 ; Hunter et Magner, 1991; Moran et al, 1991) sont surtout obtenus en phase de croissance. À l'âge adulte, les écarts ne sont pas significatifs (Utley et al, 1976; Jones, 1982; Goodman et al, 1982) car le développement osseux et musculaire est achevé et la maturité sexuelle atteinte, de façon comparable à ce qui est observé chez la femelle après traitement par les œstrogènes.

\section{L'association d'un œstrogène et d'un progestagène}

Les seules associations utilisées chez les bovins castrés sont à base d'E17 $\beta$ (ou $E 17 \beta$-benzoate) combiné à de la progestérone (ou éventuellement de l'acétate de mélengestrol). L'amélioration permise (Kahl et al, 1978 ; Prior et al, 1978 ; Rumsey, 1978 ; Harris et al, 1979 ; Rumsey, 
1982 ; Murray et al, 1983 ; Basarab et al, 1984 ; Gopinah et Kitts, 1984 ; Lemieux et al, 1988 ; Apple et al, 1991) est le plus souvent légèrement inférieure $(+16 \%, \mathrm{ET}=$ $20 \%$, soit $+0,17 \mathrm{~kg} / \mathrm{j}$ ) à celle permise par les associations contenant un androgène.

En résumé, les associations d'un androgène et d'un cestrogène apparaissent comme les préparations permettant la stimulation la plus importante des performances en terme de vitesse de croissance chez le mâle castré (bovin ou ovin) et dans une mesure légèrement moindre chez le mâle entier. Chez la femelle et le castrat, les androgènes paraissent avoir une efficacité légèrement supérieure aux œstrogènes. La stimulation de croissance chez les bovins et les ovins apparaît d'amplitude comparable.

\section{Principaux facteurs de variation de la réponse aux anabolisants}

\section{Facteurs dépendants de l'animal}

Lors d'implantations précoces chez le mâle entier, l'effet des différents anabolisants seuls ou en association est minime (fig 4). La courbe de croissance des animaux implantés peut s'infléchir sous celle des témoins (Van der Wal et Berende, 1984), probablement du fait d'une très forte sensi-

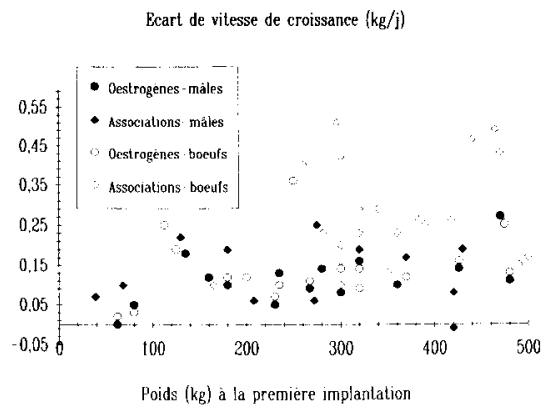

Fig 4. Effet du poids au traitement sur l'écart de vitesse de croissance entre bovins témoins et ceux traités par diverses préparations anabolisantes (implantation unique). bilité de l'axe hypothalamo-hypophysaire au feed-back négatif des stéroïdes à cette période (Amann et Walker, 1983). Le poids optimal au traitement semble donc se situer aux alentours de 200 à $250 \mathrm{~kg}$, mais peut varier en fonction du type de carcasse recherchée. Chez le bœuf, le poids à l'implantation semble être de moindre importance (fig 4), dans la mesure où, d'une part, les animaux sont en général traités après $150 \mathrm{~kg}$ de poids vif (Utley et al, 1980 ; Turner et al, 1981 ; Newbold et al, 1988) et, d'autre part, l'implant utilisé est constitué par une association d'androgène et d'œstrogène (Galbraith et Geraghty, 1982 ; Roche et Keane, 1983).

\section{Durée de la période de mesure}

La réponse aux anabolisants est fonction de la durée séparant la mesure des performances (poids fin d'essai, poids d'abattage) de la pose de l'implant (fig 5) à même fréquence de traitement. La durée maximale moyenne d'efficacité des associations est de l'ordre de 100 (entre 50 et 150 jours) chez l'animal castré ou entier, les différences disparaissant ensuite (Gielen et al, 1982 ; Fischer et al, 1986a,b; Is-

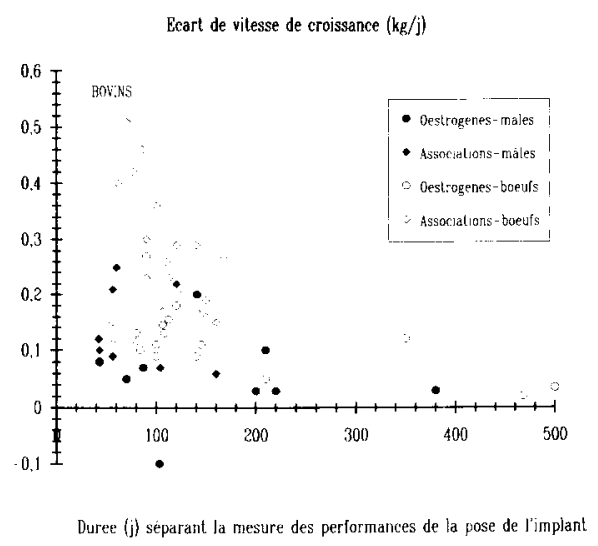

Fig 5. Effet de la durée du traitement (j) sur l'écart de vitesse de croissance entre bovins témoins et ceux traités par diverses préparations anabolisantes (implantation unique). 
tasse et al, 1988). Pour les œstrogènes, des formulations d'implants hormonaux à libération lente permettent d'obtenir des réponses positives même après $500 \mathrm{j}$ de traitement (Utley et al, 1980 ; Turner et al, 1981 ; Southgate et al, 1988) alors que les formes classiques d'implants œstrogéniques n'ont en moyenne qu'une efficacité de moins de $200 \mathrm{j}$ (Staigmiller et al, 1985 ; Vanderwert et al, 1985a). Chez les ovins, les mêmes tendances ont été observées (Field et al, 1990). Compte tenu de la forme de la courbe de réponse, l'effet maximal sur le GMQ est obtenu aux alentours de 40 à 60 j après la pose de l'implant (fig 5), ce qui signifie que le dernier traitement, en cas d'implantations multiples, doit se situer environ $60 \mathrm{j}$ avant l'abattage. En réalité, compte tenu du délai d'attente généralement supérieur à cette durée, la législation antérieure ne permettait donc pas de bénéficier de l'effet maximal sur la vitesse de croissance, ce qui a pu concuire en pratique à des utilisations frauduleuses de ces molécules.

\section{Posologie, répétition et mode d'administration}

L'accroissement des doses d'hormones n'a qu'un effet mineur sur la réponse aux anabolisants qu'ils soient en association (Galbraith, 1983; Sulieman et al, 1986), ou seuls (œstrogènes: Price et Makarechian, 1982 ; Cohen et al, 1987 ; Rode, 1987), car la dose à administrer est largement dépendante du stade de maturité de l'animal (cf ci-dessus) et de la disponibilité en récepteurs des tissus cibles, ces deux facteurs étant par ailleurs liés. Cependant les résultats obtenus sur bovins mâles par Istasse et al (1988) montrent un accroissement du GMQ supérieur avec une préparation $E$ $17 \beta(60 \mathrm{mg})+\mathrm{TBA}(300 \mathrm{mg})$ comparée à une préparation $E-17 \beta(40 \mathrm{mg})+$ TBA (100 $\mathrm{mg}$ ). Par ailleurs, la réduction de la perte de poids après traitement par TBA chez des bouvillons sous-alimentés nécessite d'im- planter une dose minimale de $0,8 \mathrm{mg}$ TBA par kg de poids vif (Hunter et al, 1993).

La nature des androgènes et des œstrogènes dans les associations présente des résultats assez contradictoires : Zer semble induire en association avec TBA une réponse anabolisante plus puissante que l'E17 $\beta$ dans certains essais (Kay et Reith, 1984) mais l'inverse est aussi vrai (Yasin et Galbraith, 1981; Galbraith, 1983). In vitro, Katzenellenbogen et al (1979) ont montré que des concentrations en Zer 100 fois plus fortes que celle en E17 $\beta$ sont nécessaires pour obtenir un effet utérotropique équivalent.

Bien que d'importance considérable en pratique, la nature du support des hormones dans l'implant n'a été que peu étudiée. Istasse et al (1988) ont montré que des supports constitués d'une base de cholestérol présentent une activité plus durable que des supports de lactose, alors que Bartle et al (1992) n'observent aucune différence pour la nature du support sur l'efficacité d'une même association E17 $\beta / T B A$.

La répétition du traitement est un point à considérer lors de l'utilisation en pratique des implants hormonaux (fig 6). Les implantations multiples accroissent le plus souvent la réponse aux anabolisants surtout si l'abattage a lieu plus de $150 \mathrm{j}$ après la pose, ce qui est cohérent avec nos conclusions sur la durée de l'efficacité du traitement. Cependant l'effet positif supplémentaire paraît faible dans le cas du traitement par les œstrogènes et de toute façon toujours plus faible que l'effet induit par la première implantation dans le cas des associations.

\section{Niveau d'alimentation}

En phase de sous-alimentation ou de récupération de poids (Hunter, 1989), la Test à dose physiologique ou pharmacologique est incapable de réduire la perte de poids ou d'améliorer la vitesse de croissance, 
l'efficacité alimentaire ou de réduire le métabolisme lors de sous-alimentation. À l'opposé, TBA réduit le métabolisme de jeûne, accroît l'efficacité alimentaire (Hunter et Vercoe, 1987) et, dans certains cas, il limite la perte de poids (Hunter et Magner, 1990a). Ces différences entre TBA et Test peuvent être reliées aux différences de mode d'action de ces 2 androgènes au niveau de la protéosynthèse et de la protéolyse et donc du coût énergétique de ces process (cf revue de Schmidely, 1993).

De façon comparable aux résultats obtenus avec TBA seul, l'association E17ß/ TBA permet de réduire la perte de poids et le métabolisme dans la majorité des expériences de sous-alimentation (Stafford et al, 1981 ; Galbraith et Geraghty, 1982) à l'exception des résultats de Lobley et al (1985) pour lesquels l'âge au traitement est plus précoce que pour les 2 expérimentations précédentes.

\section{Interaction avec la teneur en azote de l'aliment}

L'analyse intra-expérience des essais où la teneur en protéines de la ration varie per-

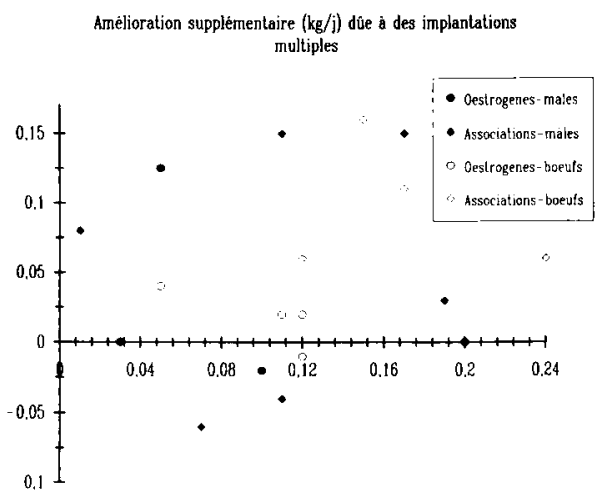

Amélioration de la vitesse de croissance $(\mathrm{kg} / \mathrm{j})$ due à une implantation unique

Fig 6. Efficacité comparée de l'amélioration des performances de croissance par une ou plusieurs implantations de diverses préparations anabolisantes chez les bovins. met de montrer que l'accroissement de l'apport d'azote dans la ration augmente l'écart de gain après traitement par des œstrogènes (Rhind et al, 1984 ; Newbold et al, 1988), des androgènes (Hunter et Vercoe, 1987; Hunter, 1989) ou des associations (Murray et al, 1983 ; Steen, 1988).

Par ailleurs, l'analyse inter-expériences (fig 7) permet de montrer un rôle limitant de l'azote de la ration dans la réponse aux anabolisants, sur un échantillon de données où la teneur en protéines de la ration varie entre 2,2\% (Hunter, 1989) et $23 \%$ (aliment lacté, Toullec et Manis, 1986). Compte tenu des facteurs de variations étudiés ci-dessus, nous avons sélectionné, dans l'ensemble des essais publiés sur bovins de tous sexes, les expérimentations où la durée des essais n'excédait pas $200 \mathrm{j}$, où les animaux étaient traités par les anabolisants au-delà de $150 \mathrm{~kg}$ de poids vif, et où le taux azoté de la ration était explicitement indiqué ; ces données $(n=63)$ ont été analysées par le modèle linéaire d'analyse de variance suivant :

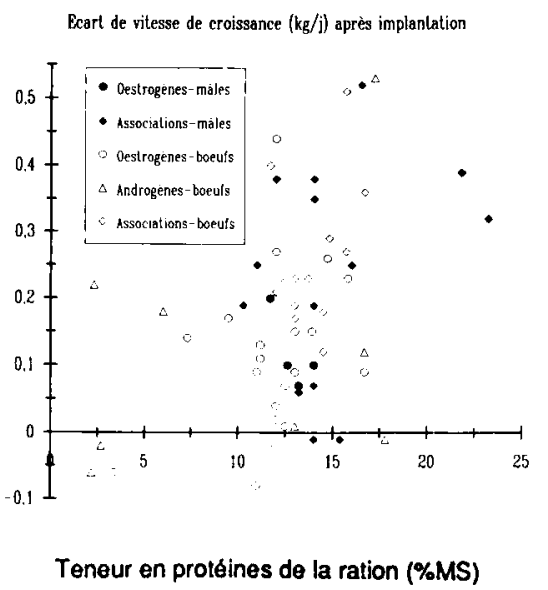

Fig 7. Influence de la teneur en protéines de la ration sur l'écart de vitesse de croissance entre bovins témoins et ceux implantés par diverses préparations anabolisantes. 
Écart de GMQ (Implant - Témoin $)=$ $\mu+$ sexe + hormone $($ sexe $)+\alpha^{*}$ Dur $+\beta$ $\times$ Dur $^{2}+\chi^{*}$ Prot $+\delta \times$ Prot $^{2}+\varepsilon_{\mathrm{ijk}}$

avec hormone(sexe): effet hormone (œstrogène, androgène, associations) hiérarchisé sur l'effet sexe (mâle, femelle, castrat) ; Dur: durée (j) séparant l'implantation de la mesure du GMQ; Prot : taux de protéines $(N \times 6,25)$ en \% de la matière sèche de la ration.

Chacun des termes du modèle est significatif au seuil de $5 \%$, et le modèle apparaît hautement significatif : $R^{2}=0,45$ $(P<0,001)$. Au travers de ce modèle, les effets des œstrogènes sur l'augmentation du GMQ chez les mâles et les castrats sont respectivement de $+0,06 \mathrm{~kg} / \mathrm{j}$ ( $E T=$ $0,06)$ et $+0,10 \mathrm{~kg} / \mathrm{j}(E T=0,04)$; ceux des androgènes chez la femelle et le castrat sont respectivement de $+0,13 \mathrm{~kg} / \mathrm{j}$ ( $E T=$ $0,05)$ et $+0,14 \mathrm{~kg} / \mathrm{j}(E T=0,06)$; ceux des associations chez le mâle et le castrat sont respectivement de $0,19 \mathrm{~kg} / \mathrm{j}(E T=$ $0,06)$ et de $+0,25 \mathrm{~kg} / \mathrm{j}(E T=0,06)$. Ces valeurs apparaissent proches des valeurs maximales calculées en «Performances de croissance et efficacité alimentaire», ce qui est logique compte tenu, d'une part, des critères sélectionnés ci-dessus et, d'autre part, du fait que le GMQ des animaux témoins de cet échantillon est proche de $1,1 \mathrm{~kg}$ (valeur optimale pour l'accroissement des performances). Sur cet échantillon, les coefficients des covariables Dur, Dur2, Prot et Prot ${ }^{2}$ sont respectivement $\alpha=4,08 \mathrm{EE}-3(\mathrm{ET}=2,3 \mathrm{EE}$ 3), $\beta=-3,25 \mathrm{EE}-5$ ( $\mathrm{ET}=0,95 \mathrm{EE}-5), \chi=$ $5,32 \mathrm{EE}-2$ ( $\mathrm{ET}=2,2 \mathrm{EE}-2$ ) et $\delta=-1,45$ EE-3 (ET $=, 87$ EE-3). Ces coefficients montrent que :

i) toutes choses égales par ailleurs, l'amélioration des performances de croissance après implantation passe par un optimum de durée voisin de $60 \mathrm{j}$ sur cet échantillon de données, ce qui est cohérent avec l'ensemble de nos conclusions ci-dessus. ii) sur cet échantillon de données, l'accroissement de la teneur en protéines de la ration jusqu'au niveau de $18 \%$ accroît l'écart de GMQ entre témoins et animaux traités, l'écart diminuant au-delà de cette valeur, bien que peu d'essais aient utilisé des taux azotés supérieurs à $18 \%$ pour des raisons pratiques. Ceci doit donc conduire en pratique à maximiser la teneur en azote de la ration, et ce d'autant que la composition du gain après traitement est plus riche en protéines (voir "Effet des anabolisants sur la composition corporelle, la qualité des carcasses et de la viande »).

\section{Efficacité alimentaire chez les animaux alimentés ad libitum}

Chez les bovins, l'accroissement de la matière sèche ingérée après traitement par les anabolisants est de l'ordre de $3 \%$ (ET = $8 \%$ ), l'effet stimulateur se manifestant surtout avec les associations chez le bœuf ( $+6 \%$ en moyenne) avec des écarts pouvant atteindre $1,7 \mathrm{~kg} \mathrm{MS}$ (Rumsey, 1978). Chez les moutons castrés, les androgènes et les associations semblent accroitre l'ingestion de la même façon. Ces effets sont dus aux actions bien connues des œstrogènes et des androgènes lorsqu'ils sont administrés à faible dose ( $c f$ revue de Wade et Gray, 1979).

L'accroissement d'ingestion n'est cependant pas proportionnel à l'accroissement du gain. Sur l'ensemble des données de la bibliographie (tous sexes et toutes molécules confondus), la relation entre l'indice de consommation des animaux implantés (IC (Imp)) et celui des témoins (IC (Tem) :

$$
\begin{aligned}
\mathrm{IC}(\mathrm{Imp}) & =\mathrm{IC}(\text { Tém })^{\star} \exp [-0,0068(\mathrm{~s}=0,0008) \\
& \star((\mathrm{GMQ}(\mathrm{Imp}) / \mathrm{GMQ}(\text { Tém }))-1)] \\
\mathrm{R}^{2} & =0,70, \mathrm{n}=121 \\
\mathrm{ETR} & =0,60 \mathrm{~kg} \mathrm{MS} / \mathrm{kg} \mathrm{GMQ}
\end{aligned}
$$


montre que, pour des améliorations de GMQ comprises entre 10 et $20 \%$ (cf "Amplitude des améliorations"), I"IC après implantation est réduit de 7 à $13 \%$, et jusqu'à $40 \%$ dans le cas de fortes améliorations de la vitesse de croissance (SinnetSmith et al, 1983). À l'opposé, lors de diminution du GMQ due au traitement par les œstrogènes (Ford et Gregory, 1983 ; Hopkins et Dikeman, 1987), les animaux traités sont métaboliquement de moins bons transformateurs (IC accru), ce qui pourrait être lié à l'absence de modification du métabolisme d'entretien (voire à son accroissement) par les œstrogènes, aux modifications de composition corporelle (of 347) ainsi qu'aux modifications respectives des taux de synthèse et de dégradation protéique (cf revue de Schmidely, 1993).

\section{EFFETS DES ANABOLISANTS SUR LA RÉTENTION AZOTÉE}

L'accroissement de la rétention azotée par des androgènes (Van der Wal et al, 1975; Galbraith, 1980; Hunter et Magner, 1990a; Lobley et al, 1990), des œstrogènes (Van der Wal et al, 1985b; Lambot et al, 1983b ; Williams et al, 1991) ou des associations (Van der Wal et al, 1975b ; Griffiths, 1982 ; Grantley-Smith et al, 1983 ; Lambot et al, 1983a,b ; Lobley et al, 1983 ; Singh et al, 1984 ; Lobley et al, 1985 ; Toullec et Manis, 1986 ; istasse et al, 1988 ; Hunter et Magner, 1990b) n'est pas dû à une augmentation de la digestibilité de l'azote de la ration, mais à une réduction de l'élimination urinaire d'urée consécutive à un abaissement de l'urée plasmatique, du fait d'une réduction du catabolisme protéique principalement sous l'action de TBA (Vernon et Buttery, 1976, 1978a,b).

De nombreux facteurs de même nature que ceux identifiés pour la vitesse de croissance influencent l'efficacité des anabolisants sur l'augmentation de la rétention azotée et la diminution de l'urée plasmatique. Lors d'implantation unique ou répétée par des associations chez les bovins, l'accroissement de rétention azotée (dNRT, g/ j) passe par un maximum (fig 8), qui peut être calculé à partir des données citées cidessus ( $n=23$ comparaisons) suivant l'ajustement :

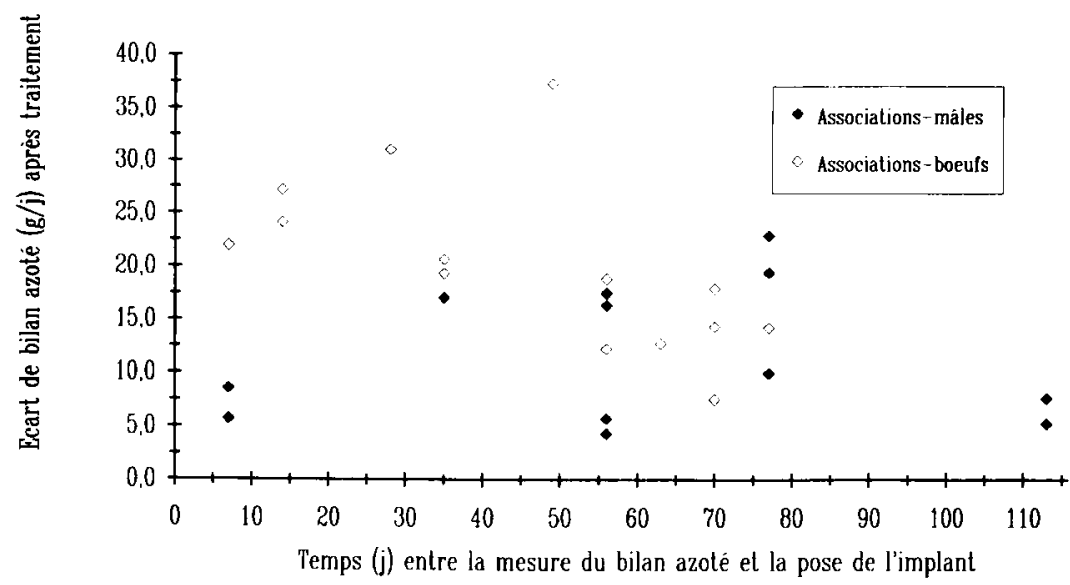

Fig 8. Influence de l'intervalle entre la mesure du bilan azoté et la pose de l'implant chez les bovins traités par des associations d'anabolisants. 


$$
\begin{aligned}
\mathrm{dNRT} & =3,93(\mathrm{~s}=0,09) \\
& \times \exp (-0,039(\mathrm{~s}=0,01) \times t) \\
& \times 0,945(\mathrm{~s}=0,03)
\end{aligned}
$$

où $t$ est le temps (j) séparant le traitement de la mesure du bilan azoté.

Le maximum de dNRT d'après cette équation est situé vers $24 \mathrm{j}$, ie aux alentours de la $3^{\mathrm{e}}$ ou $4^{\mathrm{e}}$ sem après traitement (Lambot et al, 1983a,b; Lobley et al, 1985 ; Istasse et al, 1988), alors que l'effiacité maximale en terme de GMQ apparaît un peu plus tardive (40 à $60 \mathrm{j}$ ) : le fait que les échantillons de données pour calculer dNRT d'une part et GMQ d'autre part ne sont pas strictement les mêmes peut expliquer ces variations. L'efficacité du traitement est réduite ultérieurement, les urémies sanguines pouvant même dépasser celles des animaux témoins (Lobley et al, 1982 ; Lobley et al, 1985). L'effet d'une seconde implantation est par ailleurs toujours plus faible qu'un implant unique et peut même s'annuler lors d'implantations ultérieures. Enfin, chez le veau mâle alimenté au lait, la nature de l'énergie (lipides vs glucides) peut influencer l'accroissement de rétention azotée : celle-ci est plus forte avec les glucides (Toullec et Manis, 1986), ce qui pourrait être dû à un accroissement de l'activité de l'axe insulinique et une meilleure captation des acides aminés plasmatiques.

Sur l'ensemble des données citées cidessus, et concernant les bovins castrés ou mâles, témoins ou traitées par des associations œestrogène/androgène ou des androgènes (TBA principalement), la relation (fig 9) entre rétention azotée (NRT, g/j) et le GMQ ( $\mathrm{kg} / \mathrm{j})$ a été ajusté au modèle :

$$
\begin{aligned}
\mathrm{GMQ} & =0,09(\mathrm{~s}=0,01)+1,94 \\
& \times(1-\exp (-0,023(\mathrm{~s}=0,007) \times \mathrm{NRT}),
\end{aligned}
$$

$$
\mathrm{ETR}=0,19 \mathrm{~kg} / \mathrm{j}, n=45 \text { lots. }
$$

L'analyse des résidus de cette relation montre que la prédiction du GMQ est sous-estimée chez les animaux traités par

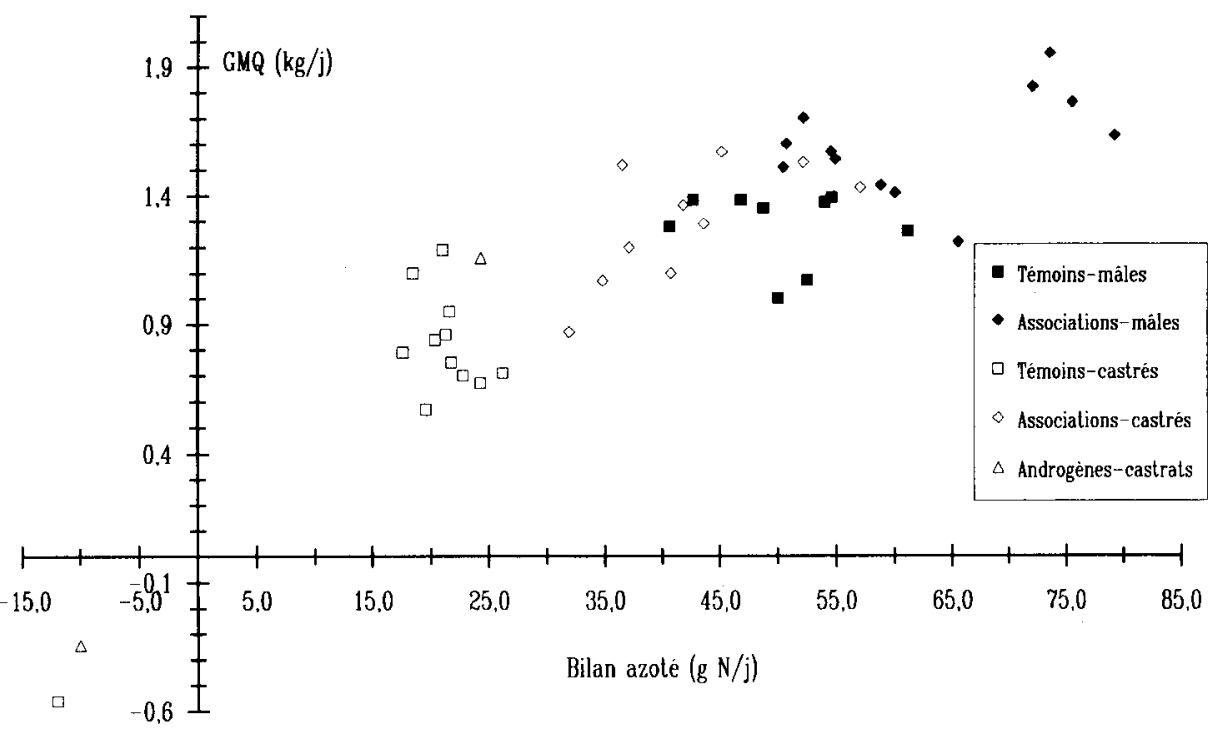

Fig 9. Relation entre vitesse de croissance et bilan azoté chez des bovins mâles ou castrés, traités ou non par des préparations anabolisantes. 
les anabolisants surtout en ce qui concerne les castrats, ce qui pourrait refléter, d'une part, des différences de composition corporelle, plus marquées après traitement chez les castrats que chez les individus mâles ( $c f$ "Composition de la carcasse»), et, d'autre part, une réduction du besoin d'entretien après traitement par TBA compatible avec nos conclusions (voir "Amplitude des améliorations") et le mode d'action supposé de TBA.

\section{EFFET DES ANABOLISANTS SUR LA COMPOSITION CORPORELLE, LA QUALITÉ DES CARCASSES ET DE LA VIANDE}

\section{Conformation et état d'engraissement de la carcasse}

Un critère économique important pour les engraisseurs est constitué par le rendement en carcasse $(\rho)$. Chez les ovins et les bovins mâles ou castrés, l'analyse de $\rho$ a été effectuée selon le modèle :

$\rho=\mu+$ hormone + sexe + hormone $x$ sexe $+\alpha \times$ Poids (fin d'essai) $+\varepsilon$.

Cette analyse (tableau II) montre, sur cet échantillon de données, que :

i) le mâle entier présente un rendement légèrement supérieur au castrat ;

ii) l'effet des anabolisants paraît assez faible. Les œstrogènes sont ceux qui ont l'effet le plus marqué chez les bovins (Galbraith et Watson, 1978; Martin et Stobb, 1978 ; Fischer et al, 1986a ; Southgate et al, 1988) alors que l'effet des associations (et des androgènes seuls, non testé ici pour cause d'effectifs insuffisants) est globalement peu important.

L'influence des anabolisants sur la conformation est un peu plus prononcée mais suit les mêmes tendances que celles observées sur le rendement. Les œstrogènes améliorent la conformation des mâles entiers (Fischer et al, 1986b, Peters et al, 1988) alors que, chez le mâle castré, leur effet et celui des associations androgène/œstrogène est faible (Wiggins et al, 1979 ; Steen, 1985 ; Fischer et al, $1986 a, b)$. Les modifications éventuelles de conformation s'accompagnent parfois d'un changement des caractéristiques de carcasse: sa longueur ainsi que la profondeur du thorax et la largeur des côtes s'accroissent dans certains essais (Coelho et al, 1981 ; Yasin et Galbraith, 1981 ; Coehlo et al, 1986) avec une réduction de la part des gigots surtout après traitement par des androgènes. Cependant, d'autres auteurs n'obtiennent aucune modification chez les bovins ou ovins entiers ou castrés (Vanderwert et al, 1985b; Sulieman et al, 1986 ; Sulieman et al, 1988): ces différences peuvent être attribuées aux différents âges au traitement (maturité squelettique différente) pour lesquels la priorité de développement des différents morceaux de la carcasse est variable.

Les modifications de l'état d'engraissement après traitement chez les bovins et les ovins à l'abattage ont été étudiées par l'analyse de 2 critères les plus fréquemment cités : les quantités de gras pelvien + périrénal, et l'épaisseur du tissu adipeux sous-cutané sur le long dorsal chez les bovins par le même modèle que celui utilisé pour le rendement $\rho$. Chez les bovins (tableau II), les 2 critères n'apparaissent pas aussi précis ( $c f$ la comparaison des valeurs de l'erreur standard de la moyenne rapportées à la moyenne du critère) : la quantité de gras pelvien + périrénal semble être plus fortement influencée par les anabolisants que celle du gras souscutané, probablement du fait d'une plus grande standardisation de cette mesure. Ceci permet d'expliquer les résultats contradictoires obtenus à partir des me- 


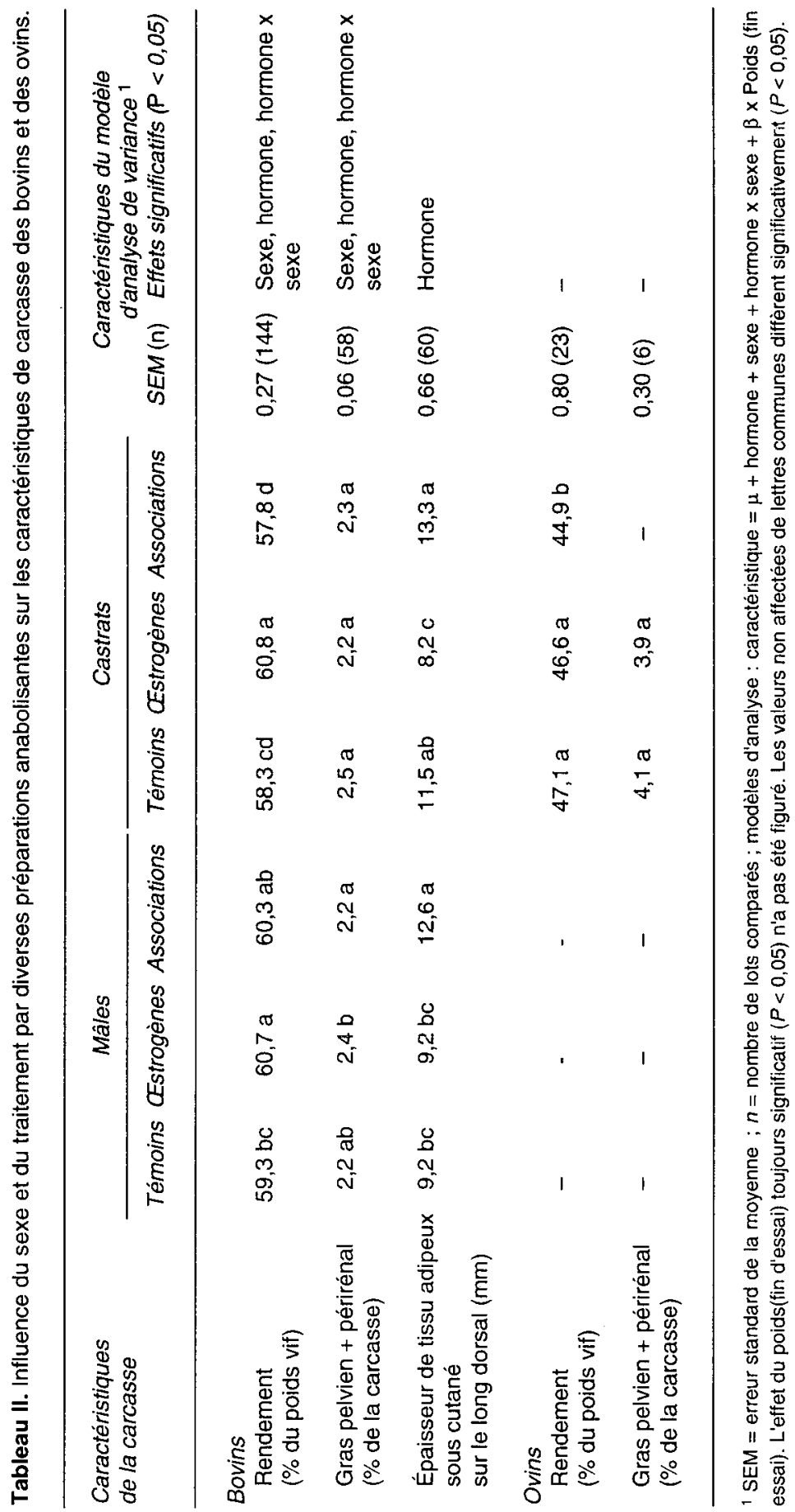


sures de gras sous-cutanés chez le bovin mâle (Vanderwert et al, 1985b; Calkins et al, 1986 ; Unruh et al, 1986b ; Hopkins et Dikeman, 1987) ou la génisse (Croose et al, 1987 ; St John et al, 1987), et ce en dépit d'activités enzymatiques lipogéniques réduites dans le tissu adipeux souscutané (Burch et al, 1982). À l'opposé, le critère basé sur le gras pelvien + périrénal permet de montrer que les œstrogènes (et les androgènes, non figurés dans l'analyse pour insuffisance de données) seuls ou en combinaison réduisent l'état d'engraissement chez le castrat ou la femelle (Vanderwert et al, 1985a; Garnsworthy et al, 1986 ; Croose et al, 1987 ; Alderson et al, 1988). L'état d'engraissement des mâles entiers apparaît non modifié, voire légèrement accru (Levy et al, 1976 ; Greathouse et al, 1983 ; Price et al, 1983 ; Vanderwert et al, 1985b ; Johnson et al, 1986 ; Silcox et al, 1986 ; Wood et al, 1986), comme l'indique l'interaction significative Hormone $\mathrm{x}$ Sexe. Cette disparité importante dans l'effet des anabolisants peut être en partie attribuée aux différences inter-sexes de secrétions hormonales endogènes, mais également à l'âge au traitement qui conditionne la priorité de développement d'un tissu adipeux par rapport aux autres (Robelin, 1986) et donc sa réponse aux traitements à partir de l'affinité des récepteurs hormonaux.

\section{Composition de la carcasse}

L'action des anabolisants sur la composition de la carcasse des ovins et des bovins, mâles, femelles et castrés a été étudiée au travers d'une analyse en composantes principales (ACP, fig 10) intégrant 76 lots comparés pour la composition de la carcasse en muscles (\%), os (\%) et gras (\%) ainsi que le GMQ, à partir des données de Levy et al (1976), Martin et Stobb (1978), Drennan et al (1981), Rum- sey et al (1981), Griffiths (1982), Lambot et al (1983a), Chaudhary et al (1985), Vanderwert et al (1985b), Fischer et al (1986a,b), Garnsworthy et al (1986), Sulieman et al (1986), Keane et Drennan (1987), Ouali et al (1988), Peters et al (1988), Southgate et al (1988), Sulieman et al (1988), Galbraith et al (1990), Schakelford et al (1992), Sulieman et al (1992).

Le premier axe $(52 \%$ de variance expliquée) traduit l'opposition entre carcasses à forte proportion de muscles chez des animaux à GMQ élevé ( $\mathrm{G}[\mathrm{GMQ}, \%$ muscle $]=$ $0,30, P<0,03$ ) et celles présentant des états d'engraissement plus marqués (opposition mâles-femelles-castrats, d'une part, et opposition bovins-ovins, d'autre part). Cet axe montre que le traitement par les anabolisants accroît le GMQ et le taux de muscles dans la carcasse au détriment du gras. Ce phénomène est nettement plus marqué chez les animaux castrés traités par des associations cestrogène/ androgène et chez la jeune femelle traitée par des androgènes ou des associations. Les caractéristiques de carcasse des femelles adultes semblent peu modifiées par le traitement aux androgènes (Faulkner et al, 1989).

En revanche, chez le mâle entier traité par des associations androgène/ œstrogène, les résultats paraissent plus variables. Par ailleurs, les œestrogènes utilisés seuls chez les mâles améliorent faiblement le GMQ et accroissent légèrement l'adiposité de la carcasse, ce qui est cohérent avec nos conclusions précédentes ( $c f$ p 347) et la revue de Patterson et Salter (1985).

\section{Composition chimique et qualité de viande}

L'effet des anabolisants sur la composition chimique de l'organisme a été étudié au 


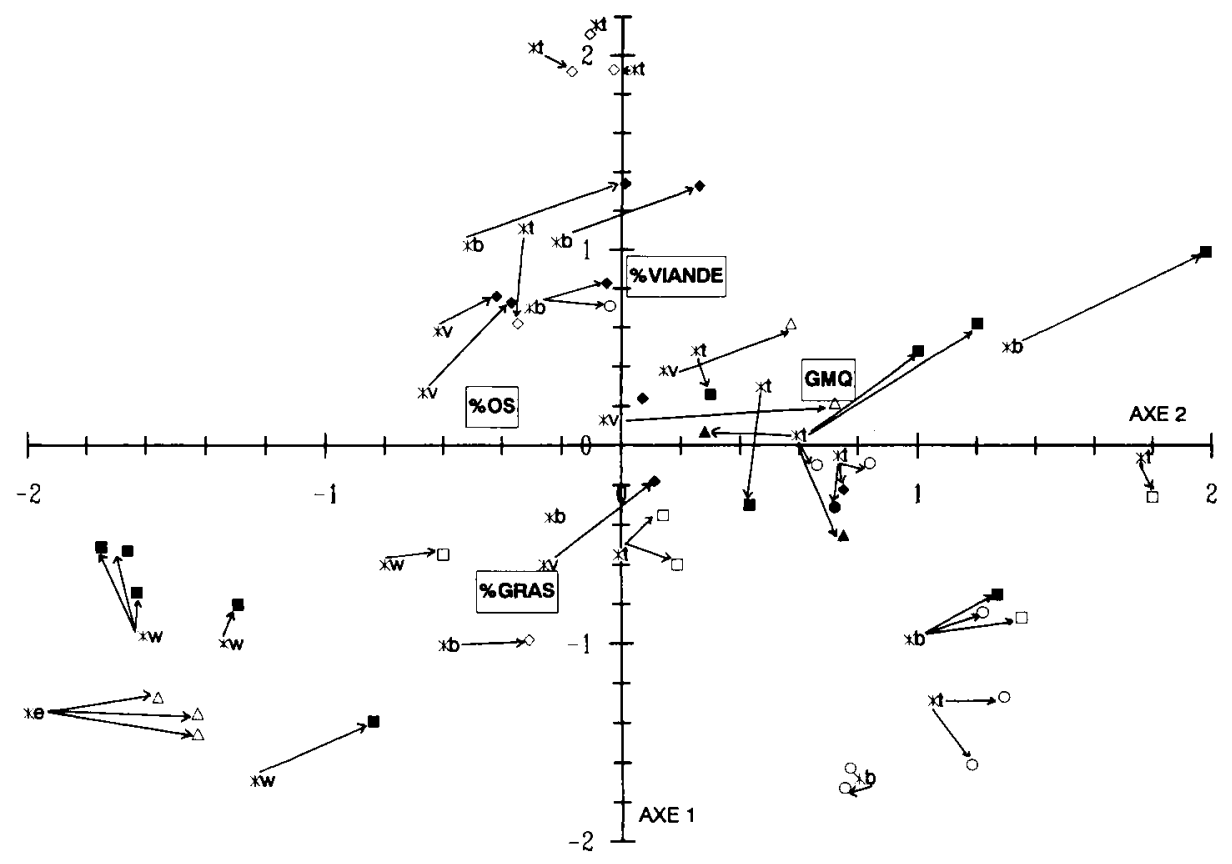

Fig 10. Représentation simultanée des variables et des individus dans le premier plan factoriel (Axe 1-2) de l'analyse en composantes principales sur les variables de carcasse sans ( $x$ : témoins) ou après traitement par diverses préparations anabolisantes $(\square$ : œestradiol-17 $\beta(O), 0$ : zéranol $(Z), 0$ : stilbènes (S), $\Delta:$ acétate de trenbolone $(T), \boldsymbol{\square}: O+T, \bullet: Z+T, \bullet: S+T, \Delta: O+$ progestérone). Les flèches indiquent l'évolution des caractéristiques des individus témoins aux individus traités. $\%$ VIANDE, \%OS, \%GRAS représentent la répartition ( $g / 100 \mathrm{~g}$ de carcasse) des muscles, des os et du gras respectivement. Codage des animaux témoins : $t=$ bovin mâle entier, $v=$ bovin femelle, $b=$ bovin castré, $e=$ ovin femelle, $w=$ ovin castré.

travers d'une ACP ( $n=69$ comparaisons, fig 11) incluant le GMQ, les pourcentages d'eau, de lipides et de protéines mesurés, soit sur la carcasse, soit sur l'ensemble de l'organisme ou enfin sur un muscle particulier (le plus souvent le long dorsal), chez les bovins et les ovins. Les données sont issues de Martin et Stobb, 1978 ; Prior et al, 1978; Coelho et al, 1981 ; Rumsey et al, 1981 ; Schanbacher et al, 1980 ; Yasin et Galbraith, 1981 ; Griffiths, 1982 ; Rumsey, 1982 ; Gregory et Ford, 1983 ; Greathouse et al, 1983; Muir et al, 1983;
Singh et al, 1985 ; Coehlo et al, 1986 ; Fischer et al, 1986a; Johnson et al, 1986 ; Silcox et al, 1986 ; Ouali et al, 1988 ; Sulieman et al, 1988 ; Bass et al, 1989b; Galbraith et al, 1990 ; Lee et al, 1990 ; Dawson et al, 1991; Hunt et al, 1991; Sulieman et al, 1992.

L'axe 1 ( $66 \%$ de variance expliquée) traduit l'opposition classique entre, d'une part, la teneur en eau (liée ici au GMQ ( $\rho[G M Q$, $\% \mathrm{H} 2 \mathrm{o}]=0,56 ; P<0,001$ ) associée à la teneur en protéines $(\rho[\% \mathrm{H} 2 \mathrm{O}, \% \mathrm{PRT}]=$ $0,84 ; P<0,0001)$ et, d'autre part, celle en 


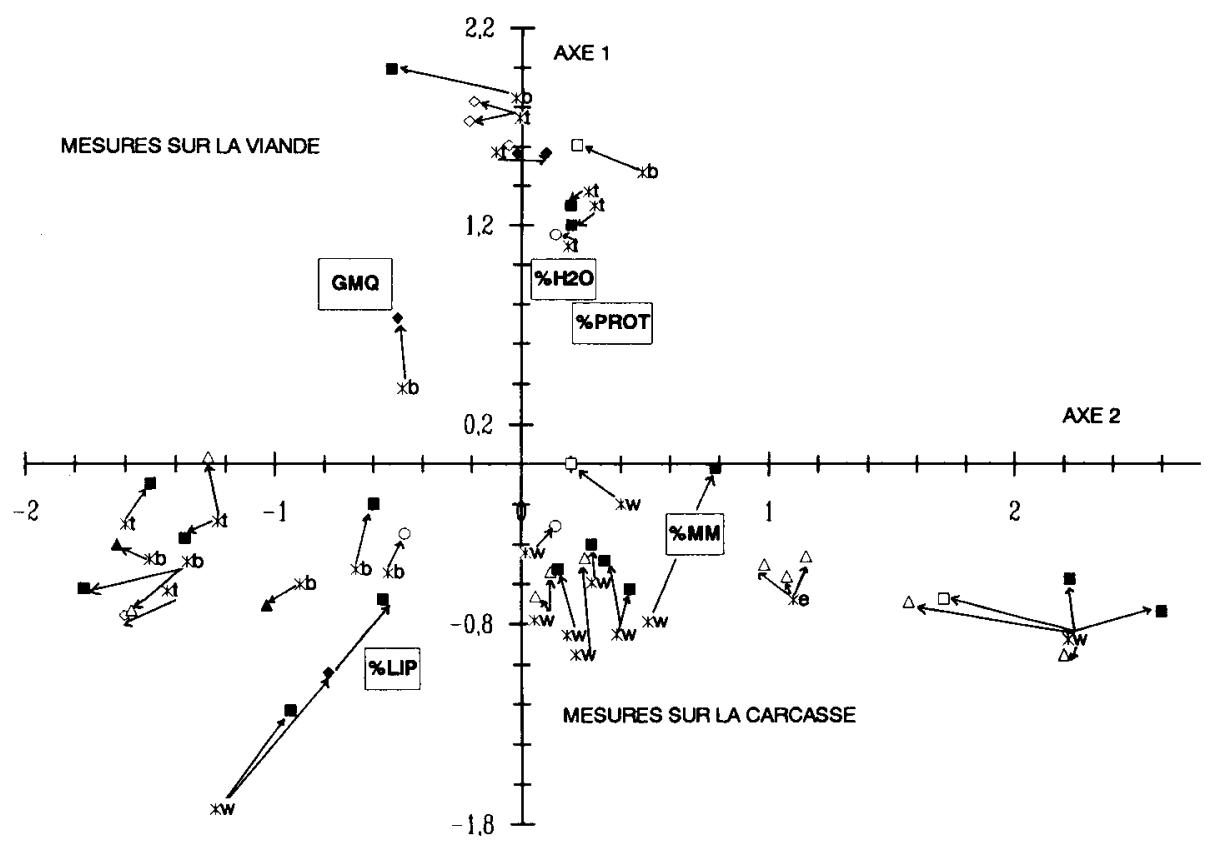

Fig 11. Représentation simultanée des variables et des individus dans le premier plan factoriel (Axe $1-2)$ de l'analyse en composantes principales sur les variables de composition chimique sans ( $x$ : témoins) ou après traitement par diverses préparations anabolisantes ( $\square:$ : nol (Z), $O$ : stilbènes (S), $\Delta:$ acétate de trenbolone $(T), \boldsymbol{\square}: \mathrm{O}+\mathrm{T}, \boldsymbol{Z}: \mathrm{T}, \boldsymbol{\bullet}: \mathrm{S}+\mathrm{T}, \mathbf{\Delta}: \mathrm{O}+$ progestérone). Les flèches indiquent l'évolution des caractéristiques des individus témoins aux individus traités. \%H2O, \%LIP, \% MM, et \%PRT : teneurs ( $\mathrm{g} / 100 \mathrm{~g}$ frais du morceau considéré) en eau, lipides, cendres et protéines respectivement. Codage des animaux témoins : $t=$ bovin mâle entier, $v=$ bovin femelle, $b=$ bovin castré, $e=$ ovin femelle, $w=$ ovin castré.

lipides des différents morceaux. II discrimine assez nettement les mesures effectuées sur la carcasse ou sur le corps vide (ayant une plus forte proportion de lipides) de celles obtenues sur la viande. Par rapport à ces relations générales, le traitement des animaux castrés par des associations réduit la teneur en lipides des carcasses ou du corps entier et accroît celle en eau, alors que le traitement par les androgènes seuls produit des résultats plus variables. Les effets au niveau de la viande sont encore plus variables : les as- sociations androgène/œstrogène et les androgènes seuls tendent à réduire la teneur en lipides et à accroître celle en eau sans modification notable de la teneur en protéines, alors que les œestrogènes seuls ou associés à de la progestérone accroissent la teneur en lipides de la viande, au moins chez le mâle entier.

L'axe $2(27 \%$ de variance expliquée) permet de moduler les conclusions précédentes en montrant que l'implantation par les androgènes (surtout TBA) seuls ou en association tend à accroître le pourcen- 
tage de protéines au moins au niveau de la carcasse, mais pas au niveau de la viande. Ceci peut être attribué au choix du muscle sélectionné dans la mesure où tous les muscles ne présentent pas le même nombre de récepteurs aux stéroïdes (Sauerwein et Meyer, 1989): les muscles caractéristiques du dimorphisme sexuel et présentant le plus grand nombre de récepteurs aux androgènes sont plutôt situés au niveau de l'avant-main.

En conclusion, l'utilisation des anabolisants autorisés par la loi Rocard de 1984 permettait une amélioration conséquente des performances de croissance chez les ruminants en production de viande, avec une réduction simultanée de l'engraissement surtout chez le mâle castré. Ces améliorations constituaient le plus souvent la marge de l'éleveur qui les utilisait, et sans conséquences néfastes pour la santé du consommateur comme l'ont montré la majorité des travaux scientifiques. Cependant l'émergence trauduleuse de molécules à activité comparable mais présentant des effets négatifs sur la santé du consommateur, d'une part, et, d'autre part, l'impossibilité de mettre en place en pratique des contrôles efficaces pour détecter ces substances ont conduit les autorités européennes à interdire l'utilisation de tous les anabolisants dans la CEE depuis 1989. Cette décision a probablement été en partie à l'origine de l'utilisation en élevage à viande des $\beta$ agonistes dont la toxicité pour le consommateur apparaît importante. Il faut noter par ailleurs que les molécules anabolisantes à activité stéroïdienne sont encore autorisées dans de nombreux pays hors CEE.

\section{RÉFÉRENCES}

Alderson EM, Scaife JR, Galbraith $H$ (1988) The effect of oestradiol-17 $\beta$ and Cimaterol given alone or in combination on lipid metabolism and CAMP concentrations in tissues of male castrated lambs. Proc Nutr Soc 47, 109A

Amann RP, Walker OA (1983) Changes in the pituitary-gonadal axis associated with puberty in Holstein bulls. J Anim Sci 57, 433-442

Anderson PT (1990) Strategies for use of trenbolone acetate in growing/finishing beef cattle system. Minnesota Nutr Conf 51, 132

Apple JK, Dikeman ME, Simms DD, Kuhl G (1991) Effect of synthetic hormones implants, singularly or in combination, on performance, carcass traits, and longissimus muscle palatability of holstein steers. I Anim Sci 69 , 4437-4448

Baker FH, Arthaud VH (1972) Use of hormone active agents in production of slaughter bulls. $J$ Anim Sci 35, 752-754

Bartle SJ, Perston RL, Brown RE, Grant DJ (1992) Trenbolone acetate/estradiol combinations in feedlot steers: dose response and implants carrier effects. J Anim Sci 70, 13261332

Basarab JA, Gould SR, Weisenburger RD (1984) Growth response of beef cattle at pasture to zeranol or progesterone-estradiol implants. Can J Anim Sci 64, 119-126

Bass JJ, Carter DW, Duganzich DM, Kirton AH, Breier BH, Gluckman RD (1989a) Effect of $17 \beta$-oestradiol on growth and IGF-1 of steers on different pasture allowances. Livestock Prod Sci 21, 303-309

Bass JJ, Fowke PJ, Duganzich DM, Peterson AJ (1989b) Effect of different doses of 17 $\beta$ oestradiol on growth and carcass composition of wether and ewe lambs. J Agri Sci (Camb) 113, 183-187

Borger ML, Wilson LL, Sink JD, Ziegler JH, Davis SL (1973) Zeranol and dietary protein level effects on live performance, carcass merit, certain endocrine factors and blood metabolites levels of steers. J Anim Sci 36, 706-711

Burch L, Scaife JR, Galbraith H (1982) Effect of anabolic steroids on lipogenic and lipolytic enzymes in sheep tissues. Horm Metabol Fies 14, 52-53

Calkins CR, Clanton DC, Berg TJ, Kinder JE (1986) Growth, carcass and palatability traits of intact males and steers implanted with zeranol or estradiol early and throughout life. J Anim Sci 62, 625-631 
Chaudhary ZI, Price MA, Butson S, Makarechian M (1985) Effect of zeranol on skeletal growth of culls cows and heifers. Can J Anim Sci 65, 511-514

Coelho JFS, Galbraith H, Topps JH (1981) The effect of combination of trenbolone acetate and oestradiol-17 $\beta$ on growth performance and blood carcass and body caracteristics of wether lambs. Anim Prod 32, 261-266

Coelho JFS, Galbraith H, Topps JH (1986) Response of wether lambs to implantation with trenbolone acetate combined with oestradiol$17 \beta$ at two levels of dietary protein. Ann Zootech 35, 315-328

Cohen RDH, Cooper JA (1983) Avoparcin, monensin and zeranol for steers finishing on barley diets. Can J Anim Sci 63, 361-365

Cohen RDH, Janzen ED, Nicholson HH (1987) Effect of repeated implantation with zeranol from bith to weaning on growth and reproduction in beef heifers. Can J Anim Sci 67, 37-42

Croose JD, Schanbacher BD, Cross HA, Seideman SC, Smith SB (1987) Growth and carcass traits of heifers as affected by hormonal treatment. J Anim Sci 64, 1434-1440

Dawson JM, Buttery PJ, Lammiman MJ, Soar JB, Essex CP (1991) Nutritional and endocrinological manipulation of lean deposition in forage fed steers. Br J Nutr 66, 171-185

Deutscher GH, Zerfoss LL, Clanton DC (1986) Time of zeranol implantation on growth, reproduction and calving of beef heifers. $J$ Anim Sci 62, 857-886

Donaldson IA, Hart IC, Heitzman RJ (1981) GH, insuline, prolactin and total thyroxine in the plasma of sheep implanted with the anabolic steroid trenbolone acetate alone or in combination with oestradiol. Res Vet Sci $30,7-13$

Donaldson IA, Heitzman RJ (1983) Reduction of urea synthesis in growing heifers implanted with trenbolone acetate. Proc Nutr Soc 42, 59A

Drennan DJ, Roche JF, L'Estrange JL (1981) Effect of monensin sodium, resorcyclic acid lactone and trenbolone acetate on performance and feed intake of finishing cattle. Ir $J$ Agric Sci 20, 113-123

Fabry J, Renaville R, Halleux V, Burny A (1983) Plasma testosterone and $\mathrm{LH}$ response to LHRH in double muscled bulls treated with TBA and zeranol. J Anim Sci 57, 1139-1146
Faulkner DB, McKeith FK, Berger LL, Kesler DJ, Parrett DF (1989) Effect of testosterone propionate on performance and carcass characteristics of heifers and cows. J Anim Sci 67, 1907-1915

Field RA, Maiorano G, Hinds FC, Murdoch WJ, Riley ML (1990) Bone ossification and carcass characteristics of wethers given silastic implants containing oestradiol. J Anim Sci68, 3663-3668

Fischer AV, Wood JD, Tas MV (1986a) Effect of some anabolic agents on the growth, carcass and tissue composition of barley-fed entire and castrated male friesian cattl. Anim Prod 42, 195-201

Fischer AV, Wood JD, Whelehan DP (1986b) The effect of a combined androgenicoestrogenic anabolic agent in steers and bulls. I. Growth and carcass composition. Anim Prod 42, 203-213

Ford JJ, Gregory KE (1983) Effect of late castration and zeranol on feedlot performance and carcass characteristics of bovine males. J Anim Sci 57, 286-291

Frisch JE, Hunter RA (1990) Influence of the growth promotant Synovex-H on growth, resistance to parasites and reproduction of cattle heifers of three breeds. J Anim Sci (Camb) 114, 107-113

Galbraith $H(1980)$ The effect of trenbolone acetate on growth, blood hormones and metabolites and nitrogen balance of beef heifers. Anim Prod 30, 389-394

Galbraith H (1983) Response of cattle and sheep to hormonal anabolic compounds. Vet Res Comm 7, 27-34

Galbraith H, Watson HB (1978) Performance, blood and carcass characteristics of finishing steers treated with trenbolone acetate and hexoestrol. Vet Rec 103, 28-30

Galbraith H, Patterson GMF (1981) Response of growing steers to monensin sodium supplementation and implantation with trenbolone acetate and hexoestrol. J Agri Sci (Camb) 97, 489-491

Galbraith H, Topps JH (1981) Effect of hormones on the growth and body composition of animals. Nutr Abs Rev (serie B) 51, 521531

Galbraith H, Geraghty KJ (1982) A note on the response of British Friesian steer to trenbo- 
Ione acetate and hexoestrol and to alteration in dietary energy intake. Anim Prod 35, 277. 280

Galbraith H, Scaife JR, Paterson GMF, Hunter EA (1983) Effect of trenbolone acetate combined with oestradiol-17 $\beta$ on the response of steers to changes in dietary protein. $J$ Agric Sci (Camb) 101, 249-251

Galbraith H, Patterson GMF, Henderson GD, Hunter EA (1984) Effect of zeranol implantation and dietary protein level on growth and blood hormones and metabolites in bulls. 84th Meeting Br Soc Anim Prod, Scaroborough, 26-28 March 1988. Anim Prod 38, 544

Galbraith $H$, Hatendi PR, Alderson EM, Scaife JR (1990) The effect of Cimaterol and oestradiol-17 $\beta$ anlone or combined on growth and body composition of wether lambs. Anim Prod 51, 311-319

Garnsworthy PC, Cole DJA, Grantley-Smith M, Jones DW, Peters AR (1986) The effect of feeding period and trenblone acetate on the potential of culled dairy cows for beef production. Anim Prod 43, 385-390

Gielen M, Bienfait JM, Lambot O, Van Eenaeme $C$, Istasse $L$ (1982) Utilisation d'implants de trenbolone-oestradiol-17 $\beta$ chez les taurillons précoces en période de croissance et/ou d'engraissement. Ann Med Vet 126, 133-146

Goodman JP, Slyter AL, Embry LB (1982) Effect of intravaginal devices and Synovex- $\mathrm{H}$ implant on feedlot performance, cyclic activity and reproductive tract characteristics of beef heifers. J Anim Sci 54, 491-495

Gopinath R, Kitts WD (1984) Growth hormone secretion and clearance rates in growing beef steers implanted with estrogenic anabolic compounds. Growth 48, 499-514

Grandadam JA, Scheid JP, Dreux H, Deroy R (1975) Influence de différentes préparations anabolisantes sur la qualité de la viande de veau. Rec Med Vet 151, 355-362

Grantley-Smith MP, Oldham, Hart IC (1983) Effect of growth hormone and anabolic steroids on $\mathrm{N}$ retention and dynamics of urea metabolism in young Frisian steers. In: Protein metabolism and nutrition, 4th Int Symposium ( $\mathrm{R}$ Pion, M Arnal, D Bonin, eds). INRA, Paris, 161-164

Gray DG, Unruh JA, Dikeman ME, Stevenson JS (1986) Implanting young bulls with zeranol from birth to four slaughter ages: III.
Growth performance and endocrine aspect. $J$ Anim Sci 63, 747-756

Greathouse JP, Hunt MC, Dikeman ME, Corah LR, Kastner CL, Kropf DH (1983) Ralgroimplanted bulls: performance, carcass characteristics, longissimus palatability and carcass electrical stimulation. J Anim Sci 57, 355-363

Gregory KE, Ford JJ (1983) Effect of late castration, zeranol and breed group on growth, feed efficiency and carcass characteristics of late maturing bovine males. J Anim Sci 56 , $771-780$

Griffiths TW (1982) Effect of trenbolone acetate and resorcyclic acide lactone on protein metabolism and growth in steers. Anim Prod 34, 309-314

Harris $\mathrm{Cl}$, Cash EH, Wilson LL, Stricklin WR (1979) Effect of concentrate level, protein source and growth promotant on growth and carcass traits. J Anim Sci 49, 613-619

Hatendi PR, Galbraith H, Scaife JR (1988) Effect of cimaterol and oestradiol-17 $\beta$ alone or combined on growth and body composition of male castrate lambs. Proc Nutr Soc 47, 108A

Heitzman RJ, Gibbons DN, Little W, Harrison LP (1981) A note on the comparative performance of beef steers implanted with the anabolic steroids trenbolone acetate and oestradiol-17 $\beta$, alone or in combination. Anim Prod 32, 219-222

Henricks DM, Edwards RL, Champe KA, Gettys TW, Skelley GC, Gimenez T (1982) Trenbolone, estradiol-17 $\beta$ and estrone levels in plas$\mathrm{ma}$ and tissues and live weight gains of heifers implanted with trenbolone acetate. $J$ Anim Sci 55, 1048-1056

Henricks DM, Gimenez T, Gettys TW, Schanbacher BD (1988) Effect of castration and an anabolic implant on growth and serum hormones in cattle. Anim Prod 46, 35-41

Hongerholt DD, Crooker BA, Wheaton JE, Carlson KM, Jorgenson JE (1992) Effect of growth hormone-releasing factor and an estradiol-trenbolone acetate implant on somatotropin, insulin-like growth factor I, and metabolites profiles in growing hereford steers. $J$ Anim Sci 70, 1439-1448

Hopkins TD, Dikeman ME (1987) Effect of oestradiol-173 implantation on performance, carcass traits, meat sensory traits and endocrine aspects of bulls and steers. Meat Sci 21, 51-65 
Hunt DW, Henricks DM, Skelley GC, Grimes LW (1991) Use of trenbolone acetate and estradiol in intact and castrate male cattle: effect on growth, serum hormones, and carcass characteristics. J Anim Sci 69, 2452-2462

Hunter RA (1989) Effect of pharmacological dose of testosterone on growth rate, feed intake and energy metabolism of steers gaining or losing weight on roughage diets. J Agric Sci (Camb) 112, 257-265

Hunter RA, Vercoe JE (1987) Reduction of energy requirements of steers fed on low-qualityroughage diets using trenbolone acetate. $\mathrm{Br}$ J Nutr 58, 477-483

Hunter RA, Vercoe JE (1988) Effect of oestradiol-17 $\beta$ on energy metabolism of steers fed roughage diets. J Agric Sci (Camb) 111, 187190

Hunter RA, Magner T (1990a) Whole body and tissue protein synthesis in steers losing weight on a low-protein-quality roughage diet: the effect of trenbolone acetate. $J$ Agric Sci (Camb) 115, 121-127

Hunter RA, Magner T (1990b) Effect of trenbolone acetate on urea metabolism in cattle fed low protein roughage diets. I Agric Sci (Camb) 114, 55-58

Hunter RA, Magner T (1991) Growth and subsequent fertility of cows implanted during pregnancy with trenbolone acetate and oestradiol. Aust J Agric Res 42, 641-645

Hunter RA, Davey JB, Buttery PJ (1987) Fractional protein synthesis in liver and in individual muscles in lambs: effect of time of sampling following te use of the continuous infusion technique. J Agric Sci (Camb) 108, 511-514

Hunter RA, Johnson CG, Frisch JE (1993) Effect of trenbolone acetate alone or in combination with oestradiol- $17 \beta$ for reducing weight loss in cattle. Aust J Agric Res 44, 1113-1122

Hutcheson JP, Greene LW, Carstens GE, Byers FM (1992) Effect of zeranol and two dietary levels of calcium and phosphorus on performance, carcass and bone characteristics, and calcium status in growing lambs. $J$ Anim Sci 70, 1346-1351

Istasse L, Evrard P, Van Eenaeme C, Gielen M, Maghuin Rogister G, Bienfait JM (1988) Trenbolone acetate in combination with oestradiol-17 $\beta$ : influence of implant supports and dose levels on animal performance and plasma metabolites. J Anim Sci 66, 1212-1223
Jones SDM (1982) Performance and carcass characteristics of cull dairy cows given testosterone-oestradiol implants. Can J Anim Sci 62, 295-297

Johnson RC, Gee DH, Costello WJ, Carlson CW (1986) Effect of anabolic implants and breed group on carcass traits and palatability characteristics of bullock beef. $J$ Anim Sci 62 , 399-406

Kahl S, Bitman J, Rumsey TS (1978) Effect of Synovex-S on growth rate and plasma thyroid hormone concentrations in beef cattle. $J$ Anim Sci 46, 232-237

Katzenellenbogen BS, Katzenellenbogen JA, Mordecai D (1979) Zearalenones: characterization of the estrogenic potencies and receptor interactions of a serie of fungal $\beta$ resorcyclic acid lactones. Endocrinol 105, 3340

Kay M, Reith TL (1984) A comparison of sequential implantation with zeranol or a single implant of oestradiol-17 $\beta$. Anim Prod 38, $544 \mathrm{~A}$

Keane MG, Drennan MJ (1987) Lifetime growth and carcass composition of heifers and steers non-implanted or sequentially implanted with anabolic agents. Anim Prod 45, 359-369

Kirkwood RN, Cohen RDH, King BD, Thacker PA (1991) The influence of zeranol implantation on growth and reproduction in beef heifers. Can J Anim Sci 71, 1253-1256

Lambot O, Van Eename C, Bienfait JM, Gielen $M$, Istasse L (1982) Effet du trenbolone associé au 17ß-oestradiol sur des taurillons de type culard et mixte en croissanceengraissement. Ann Méd Vét 126, 477-491

Lambot O, Van Eenaeme C, Gielen M, Bienfait JM (1983a) Effet des associations anabolisantes trenbolone $+17 \beta$-oestradiol, progesterone $+17 \beta$-oestradiol et du zeranol chez les jeunes taureaux en croissanceengraissement. Revue Agric (Brux) 36, 5-27

Lambot O, Van Eenaeme C, Gielen M, Bienfait JM (1983b) Effect of anabolic agents on nitrogen balance of growing bulls and culled cows. In: Protein metabolism and nutrition, 4th International Symposium (M Arnal, R Pion, D Bonin, eds), INRA, Paris, 157-160

Lee CY, Henricks DM, Skelley GC, Grimes LW (1990) Growth and hormonal response of intact and castrate male to trenbolone acetate and estradiol. J Anim Sci 68, 2682-2689 
Lemieux PG, Byers FM, Schelling GT (1988) Anabolic effect on rate, composition and energetic efficiency of growth in cattle fed torage and grain diet. J Anim Sci 66, 18241836

Levy D, Holtzer Z, Folman $Y$ (1976) Effect of plane of nutrition, diethylstilbestrol implantation and slaughter weight on the performance of Israeli-Friesian intact male cattle. Anim Prod 22, 55-59

Lindsay JA, Mullins TJ, Toleman MA, Stephenson HP (1984) The effect of trenbolone acetate on live-weight changes and pregnancy rates in zebu crossbred heifers grazing tropical pastures. Proc Aust Soc Anim Prod 15, $708 \mathrm{~A}$

Little W, Kay RM, Harwood DJ, Heitzman RJ (1979) The effect of implanting prepubertal dairy heifers with anabolic steroids on liveweight gain, blood and urine composition and milk yield. J Agric Sci (Camb) 93, 321. 329

Lobley GE, Smith JS, Mollisson G, Connel A, Galbraith $H$ (1982) The effect of an anabolic implant (trenbolone acetate + oestradiol-17 3 ) on the metabolic rate and protein metabolism of beef steers. Proc Nutr Soc 41, 28A

Lobley GE, Connel A, Harris $\mathrm{Cl}$, Milne G, Mc Diarmid R (1983) Effect of anabolic steroids (trenbolone acetate + oestradiol-17ß) on protein metabolism in growing castrated male cattle. In: Protein metabolism and nutrition, 4th International Sympsoium (M Arnal, $R$ Pion, D Bonin, eds) INRA, Paris, 69-72

Lobley GE, Connel A, Mollison GS, Brewer A, Harris Cl, Buchan V, Galbraith H (1985) The effect of a combined implant of trenbolone acetate and oestradiol-17 $\beta$ on protein and energy metabolism of growing steers. $\mathrm{Br} J$ Nutr 54, 681-694

Lobley GE, Connel A, Milne E, Buchan V, Cal$\operatorname{der} A G$, Anderson SE, Vint H (1990) Muscle protein synthesis in response to testosterone administration in wether lambs. Br J Nutr 64, 691-704

Makarechian M, Arthur PF, Price MA (1991) Effect of postweaning implantation of zeranol and dietary energy level on growth and reproductive performance of replacement beef heifers. Can J Anim Sci 71, 265-271

Martin TG, Stobb M (1978) Growth and carcass traits of Holstein steers, bulls and bulls im- planted with diethylstilbestrol. $J$ Dairy Sci 61 , 132-134

Martin TG, Perry TW, Mohler MT, Owens FH (1979) Comparison of four levels of protein supplementation with and without oral diethylstilbestrol on daily gain, feed conversion and carcass traits of bulls. J Anim Sci 48 , 1027-1031

Moran C, Quirke JF, Prendville DJ, Bourke S, Roche JF (1991) The effect of estradiol, trenbolone acetate, or zeranol, on growth rate, mammary development, carcass traits, and plasma estradiol concentrations in beef heifers. J Anim Sci 69, 4249-4258

Muir LA, Wiens $S$, Duquette PF, Rickes EL, Cordes EH (1983) Effect of exogenous growth hormone and DES on growth and carcass composition in growing lambs. J Anim Sci 56, 1315-1323

Murray DA, Burgess TD, Mowat DN (1983) Effects of feeding avoparcin in combination with progesterone-estradol implants on growing and finishing steers. Can J Anim Sci 63, 885-891

Newbold JR, Garnsworthy PC, Buttery PJ, Cole DJA, Haresign W (1988) Responses of British Friesian steers with or without implants of oestradiol-17 $\beta$ to undegradable dietary protein. Anim Prod 46, 181-193

Olsen RF, Wangness PJ, Martin RJ, Gahagan $\mathrm{JH}$ (1977) Effect of zeranol on blood metabolites and hormones in wether lambs. $J$ Anim Sci 45, 1392-1396

Ouali A, Zabari M, Renou JP, Touraille C, Kopp $\mathrm{J}$, Bonnet M, Valin C (1988) Anabolic agents in beef production: effects on muscle traits and meat quality. Meat Sci 24, 151-153

Patterson RLS, Salter LJ (1985) Anabolic agents and meat quality: a review. Meat $\mathrm{Sci}$ $14,191-220$

Payne E, Cope BC (1991) The effect of hormones, other pharmacological agents and nutrition on plasma triglycerides and carcass composition in lambs and steers. Anim Prod $53,51-60$

Peters AR, Evans DG, Read DJ, Beeby JM, Haresign $N$ (1984) Effect of trenbolone acetate and hexoestrol on live weight gain, serum hormones and metabolites concentrations in steers. Anim Prod 38, 385-390

Peters AR, Soughyate JR, Aughey E, Dixon SN (1988) The effect of oestrogenic agents on 
live weight gain, carcass composition, reproductive function and tissues residues in intensively reared beef bulls given cereal based diets. Anim Prod 47, 215-223

Phillips WA, Mc Laren JB, Cole NA (1986) The effect of a preassembly zeranol implant and post-transit diet on the health performance and metabolic profile of feeder calves. $J$ Anim Sci 62, 27-36

Price MA, Makarechian M (1982) The influence of zeranol on feedlot performance and carcass traits of culled cows and heifers. Can $J$ Anim Sci 62, 739-744

Price MA, Makarechian M, Tennessen T, Mathison GW (1983) The effect of zeranol on feedlot performance of beef bulls. Can J Anim Sci $63,803-809$

Prichard DL, Hargrove DD, Olson TA, Marshall TT (1989a) Effect of creep feeding, zeranol implant and breed type on beef production: 1). Calf and cow performance. J Anim Sci 67, 609-616

Prichard DL, Marshall TT, Hargrove DD, Olson TA (1989b) Effect of creep feeding, zeranol implant and breed type on beef production: 2) Reproduction, development and fat deposition in heifers. $J$ Anim Sci 67, 617-623

Prior RL, Croose JD, Harrison VL, Baile CA (1978) Elfazepam and Synovex-S: influence on growth and carcass characteristics of steers fed two dietary energy levels. J Anim Sci 47, 1225-1232

Prior RL, Smith SB, Schanbacher BD, Mersman HJ (1983) Lipid metabolism in finishing bulls and steers implanted with $17 \beta$ oestradioldipropionate. Anim Prod 37, 81-89

Quirke JF, Sheehan W (1981) Effects of anabolic steroids on the performance of hill and lowland lambs. Ir J Agri Res 20, 125-135

Rhind SM, Zigoyiannis D, Doney JM, Leslie JM, Hart IC (1984) Effect of zeranol implants and dietary supplement on growth rate, endocrine status and blood metabolite levels of growing lambs at pasture. Anim Prod 39, 269-276

Robelin J (1986) Composition corporelle des bovins : évolution au cours du développement et différences entre races. Thèse de doctorat d'État, université de Clermont-Ferrand II, $n^{\circ}$ 368

Roche JF, Davis WD (1983) Effect of reimplanting anabolic agents on liveweight and carcass weight of beef cattle. Vet Rec 112, 79-81
Roche JF, Keane MG (1983) Resorcylic acid lactone as an anabolic agent in cattle. Vet Res Comm 7, 45-50

Rode LM (1987) Effect of anabolic implants and ionophore on the performance of grazing steers. Can J Anim Sci 67, 461-467

Rumsey TS (1978) Effect of dietary sulphur addition and Synovex-S implants on fedlot steers fed an all concentrate finishing diet. $J$ Anim Sci 46, 463-477

Rumsey TS, Tyrell HF, Dinius DA, Moe PW, Croos HR (1981) Effect of diethylstibestrol on tissue gain and carcass merit of feedlot beef steers. J Anim Sci 53, 589-600

Rumsey TS (1982) Effect of Synovex-S implants and kilndust on tissue gain by feedlot steers. $J$ Anim Sci 54, 1030-1039

Sauerwein H, Meyer HHD (1989) Androgen and estrogen receptors in bovine skeletal muscle: relation to steroid induced allometric muscle growth. J Anim Sci 67, 206-212

Schackelford SD, Crouse JD, Savell JW, Cross HR, Schanbacher BD, Johnson DD (1992) Performance and carcass characteristics of bulls as influenced by exogenous hormones. Meat Sci 32, 387-396

Schanbacher BD, Croose JD, Ferrel CL (1980) Testosterone influences on growth, performance, carcass characteristics and composition of young market lambs. $J$ Anim Sci 51 , 685-691

Schanbacher BD, Prior RL, Smith SB (1983) Effect of castration and subdermal silastic implants containing oestradiol-17 $\beta$ dipropionate on feedlot performance and carcass characteristics of male cattle. Anim Prod 37, 73-80

Schmidely $P$ (1993) Revue bibliographique sur l'utilisation des hormones anabolisantes à action stéroïdienne chez les ruminants en croissance. II. Principaux modes d'action. Reprod Nutr Develop (sous press)

Sharpe PM, Buttery PJ, Haynes NB (1986) The effect of manipulating growth in sheep by diet or anabolic agents on plasma cortisol and muscle glucocorticoid receptors. $\mathrm{Br} J$ Nutr 56, 289-304

Silcox RW, Keeton JT, Johnson BH (1986) Effect of zeranol and trenbolone acetate on testis fonction, live-weight gain and carcass traits of bulls. J Anim Sci $63,358-368$ 
Singh SB, Galbraith $\mathrm{H}$, Henderson GD, Forbes $G$ (1984) Response of young rapidly growing lambs to trenbolone acetate combined with oestradiol-173. Proc Nutr Soc 43, 41A

Singh SB, Galbraith H, Scaife JR, Hunter EA (1985) Effect of oestrogenic and androgenic compounds on growth on body composition of male castrated lambs. Proc Nutr Soc 44, 93A

Sinnet-Sinith PA, Dumelow NW, Buttery PJ (1983) Effect of trenbolone acetate and zeranol on protein metabolism in male castrate and female lambs. Br J Nutr 50, 225-234

Southgate JR, Peters AR, Dixon SN (1988) Effect of oestradiol-17 $\beta$ or zeranol with or without trenbolone acetate on live-weight gain, carcass composition and zeranol residues in steers on a 18 month beef system. Anim Prod 47, 209-214

Stafford SJ, Galbraith H, Topps JH (1981) The effect of metabolisable energy on the response of steers to implantation with Revalor. Anim Prod 32, 378-379

Staigmiller RB, Brownson RM, Kartchner RJ, Williams 'JH (1985) Sexual development in beef bulls following zeranol implants. J Anim Sci 60, 342-351

Steen RWJ (1985) A comparison of bulls and steers implanted various oestrogenic growth promoters in a 15-month semi-intensive system of beef production. Anim Prod 41, 301308

Steen RWJ (1988) The effect of implantation with hormonal growth promoters on the response in the performance of beef cattle to protein supplementation of a silage-based diet. Anim Prod 47, 21-28

St John LC, Ekeren PA, Croose JD, Schanbacher BD, Smith SB (1987) Lipogenesis in adipose tissue from ovariectomized and intact heifers immunized against estradiol and (or) implanted with trenbolone acetate. $J$ Anim Sci64, 1428-1433

Sulieman AH, Galbraith H, Topps JH (1986) Growth performance and body composition of early weaned wether lambs treated with trenbolone acetate combined with oestradiol173. Anim Prod 43, 109-114

Sulieman AH, Galbraith H, Topps JH (1988) Growth performance and body composition of wether lambs implanted at two different initial live weights with trenbolone acetate combined with oestradiol-17ß. Anim Prod 47, 65-74
Sulieman AH, Galbraith H, Topps JH (1992) Growth performance and body composition of mature femelle sheep implanted with trenbolone acetate. Anim Prod 54, 53-58

Toullec R, Manis $Y$ (1986) Association oestradiol-acetate de trenbolone et rétention azotée chez le veau de boucherie. Bull Tech CRVZ Theix 65, 25-30

Turner HA, Phillips RL, Vavra M, Young DC (1981) The efficacy of an estradiol-silicone rubber removable implant in suckling growing and finishing steers. J Anim Sci 52, 939-944

Unruh JA (1986) Effect of endogenous and exogenous growth-promoting compounds on carcass composition, meat quality and meat nutritional value. $J$ Anim Sci62, 1441-1448

Unruh JA, Gray DG, Dikeman ME (1986a) Implanting young bulls with zeranol from birth to four slaughter ages: I. Live measurements, behavior, masculinity and carcass characteristics. J Anim Sci 62, 279-289

Unruh JA, Gray DG, Dikeman ME (1986b) Implanting young bulls with zeranol from birth to four slaughter ages. II. Carcass quality, palatability and muscle collagen characteristics. $J$ Anim Sci 62, 388-398

Utley PR, Newton GL, Ritter RJ, Mc Kormick WC (1976) Effect of feeding monensin in combination with zeranol and testosteroneestradiol implants for growing and finishing heifers. J Anim Sci 42, 754-760

Utley PR, Murphy CN, Merchant CE, Mc Kormick WC (1980) Evaluation of estradiol removable implants for growing and finishing steers calves. J Anim Sci 50, 221-225

Van der Wal P (1976) General aspects of the effectiveness of anabolic agents in increasing protein production in farm animals, in particular in bull caves. In: Anabolic agents in animal production (FC Lu, J Rendel, eds) Georg Thieme Publishers, Stuttgart, 60-78

Van der Wal P, Berende PLM, Sprietsma JE (1975a) Effect of anabolic agents on performance of calves. $J$ Anim Sci 41, 978-985

Van der Wal PP, Van Weerden EJ, Sprietsma JE, Huisman J (1975b) Effect of anabolic agents on nitrogen retention of calves. $J$ Anim Sci 41, 986-992

Van der Wal P, Berene PLM (1984) Effet des anabolisants sur les animaux de boucherie. In: Anabolisants en Production Animale (E Meissonier, ed), OIE, Paris, 77-120 
Vanderwert W, Berger LL, Mc Keith FK, Baker AM, Gonyou HW, Bechtel PJ (1985a) Influence of zeranol implants on growth, behavior and carcass traits in Angus and Limousin bulls and steers. J Anim Sci 61, 310-319

Vanderwert W, Berger LL, Mc Keith FK, Shanks D, Bechtel PJ (1985b) Influence of zeranol implants on growth carcass and palability traits in bulls and late castrates. $J$ Anim Sci 61, 537-545

Van Sickle DC (1985) Control of bone growth. J Anim Sci 61, (suppl 2), 76

Vernon BG, Buttery PJ (1976) Protein turnover in rats treated with trienbolone acetate. $B r J$ Nutr 36, 575-579

Vernon BG, Buttery PJ (1978a) Protein metabolism of rat treated with trienbolone acetate. Anim Prod 26, 1-9

Vernon BG, Buttery PJ (1978b) The effect of trenbolone acetate with time on the various responses of protein synthesis of the rat. $\mathrm{Br} \mathrm{J}$ Nutr 40, 563-5725

Wade GN, Gray JM (1979) Gonadal effects on food intake and adiposity: a metabolic hypothesis. Physiol Behav 22, 583-593

Wangness PJ, Olsen RF, Martin RJ (1981) Effects of breed and zeranol implantation on serum insulin, somatomedin-like activity and fibroblast proliferative activity. J Anim Sci 52, 57-62
Wiggins JP, Rothenbacher H, Wilson LL, Martin RJ, Wangness PJ, Ziegler JH (1979) Growth and endocrine response of lambs to zeranol implants: effect of preimplant growth rate and breed of sire. J Anim Sci 49, 291-297

Williams JE, Miller SJ, Mollet TA, Grebing SE, Bowman DK, Ellersieck MR (1987) Influence of frame size and zeranol on growth, composition of growth and plasma hormones characteristics. J Anim Sci 65, 1113-1123

Williams JE, Ireland SJ, Mollett TA, Hancock DL, Beever EE, Hannah S (1991) Influence of zeranol and breed on growth composition of gain, and plasma hormone concentrations. $J$ Anim Sci 69, 1688-1696

Wood JD, Fischer AV, Whelehan OP (1986) The effects of a combined androgenicoestrogenic anabolic agent in steers and bulls. 2 . Muscle weight distribution, partition of body fat and carcass value. Anim Prod 42, 213. 222

Yasin ARM, Galbraith $H$ (1981) A note on the response of wether lambs to treatment with trenbolone acetate combined with oestradiol$17 \beta$ or zeranol. Anim Prod 32, 337-340

Zarkawi A, Galbraith H, Hutchinson JSM (1991) Influence of trenbolone acetate, zeranol and oestradiol-17 $\beta$ implantation on growth performance and reproductive functions in beef heifers. Anim Prod 52, 249-253 